ARGESIM REPORT ARGESIM REPORT ARGESIM REPORT ARGESIM REPORT

\title{
EUROSIM 2019 Abstract Volume
}

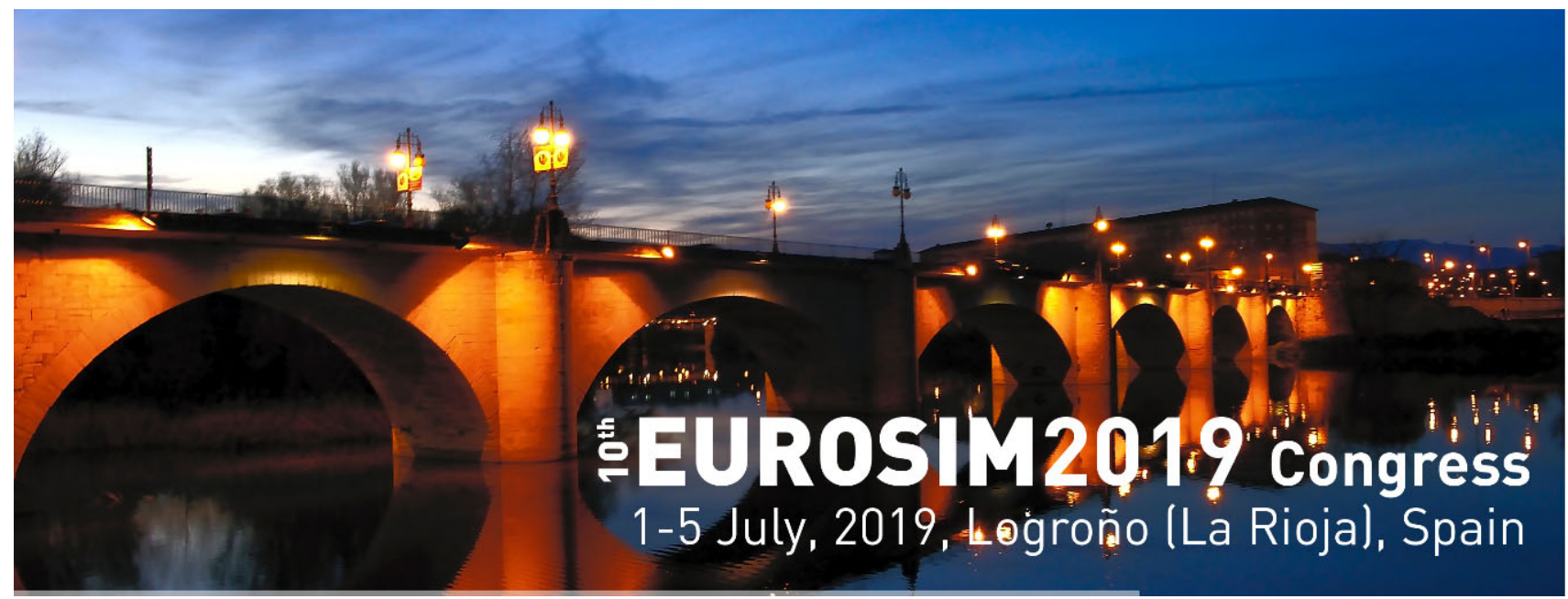

Abstracts of the 10th EUROSIM Congress on Modelling and Simulation

Logroño, La Rioja, Spain, July 1-5, 2019

Emilio Jiménez, Juan Ignacio Latorre (eds.) 



\title{
EUROSIM 2019
}

\section{Abstract Volume}

\section{Abstracts of the 10th EUROSIM Congress on Modelling and Simulation Logroño, La Rioja, Spain}

Logroño, La Rioja, Spain, July 1-5, 2019

\author{
Edited by
}

Emilio Jiménez, Juan Ignacio Latorre 


\section{Bibliographic Data:}

Publisher: ARGESIM Publisher, Vienna

Title: EUROSIM 2019 Extended Abstract Volume

Subtitle: Abstracts of the 10th EUROSIM Congress on Modelling and Simulation,

Logroño, La Rioja, Spain, July 1-5, 2019,

Author(s):

Editor(s): Emilio Jiménez, Juan Ignacio Latorre

Series: ARGESIM Reports

Series Editors: Felix Breitenecker (EUROSIM), Thorsten Pawletta (ASIM)

Volume: ARGESIM Report no. 58

ISBN: 978-3-901608-92-6 (ebook)

DOI: $10.11128 /$ arep.58

Publication Date: June 29, 2019

Number of Pages: $64+$ vi pages

Cover: Logrono Bridge Picture, from Congress Website www.eurosim2019.com

Copyright $\odot 2019$ ARGESIM Publisher

\section{Copyright Information / Regulations ARGESIM}

ARGESIM is a non-profit scientific society generally aiming for dissemination of information on system simulation - from research via development to applications of system simulation. ARGESIM's primary publication is the journal SNE - Simulation Notes Europe with open access to all contributions; generally, the authors retain the copyright of their SNE contributions. This copyright regulation holds also for ARGESIM Reports and ARGESIM Advances in Simulation publishing conference volumes for ASIM, MTHMOD, and EUROSIM (in consideration of copyright regulations for related conference publications) and monographs on system simulation (mainly $\mathrm{PhD}$ theses).

\section{About ARGESIM}

ARGESIM is a non-profit society generally aiming for dissemination of information on system simulation from research via development to applications of system simulation. ARGESIM is closely co-operating with EUROSIM, the Federation of European Simulation Societies, and with ASIM, the German Simulation Society. ARGESIM is an 'outsourced' activity from the Mathematical Modelling and Simulation Group of TU Wien, there is also close co-operation with TU Wien (organisationally and personally). ARGESIM Publisher organizes publishing activities, with ISBN root 978-3-901608-xx-y and DOI root 10.11128/xx...X.

ARGESIM's activities are:

- Publication of the scientific journal SNE - Simulation Notes Europe (Membership Journal of EUROSIM, the Federation of European Simulation Societies) $\rightarrow$ www.sne-journal.org

- Organisation and Publication of the ARGESIM Benchmarks for Modelling Approaches and Simulation Implementations $\rightarrow$ www.argesim.org/benchmarks/

- Publication of the series ARGESIM Reports (for monographs in system simulation, and proceedings of simulation conferences and workshops) $\rightarrow$ www.argesim.org/publications/

- Publication of the special series FBS Simulation - Advances in Simulation / Fortschrittsberichte Simulation (monographs in co-operation with ASIM, the German Simulation Society

- Organisation of the Conference Series MATHMOD Vienna (triennial, in co-operation with EUROSIM, ASIM, and TU Wien) $\rightarrow$ www.mathmod.at

- Organisation of Summerschools and Seminars on Mod\&Sim

- Administration and support of ASIM (German Simulation Society $\rightarrow$ www.asim-gi.org) and of EUROSIM (Federation of European Simulation Societies $\rightarrow$ www.eurosim.info)

- Support of ERASMUS and CEEPUS activities in system simulation for TU Wien

ARGESIM - Arbeitsgemeinschaft Simulation News - Working Committee Simulation News - SNE Publication Mommsengasse 19/8, 1040 Vienna, Austria; Tel +43-1-58801-10111, -10115; Fax +43-1-58801-910111 Email: office@argesim.org, office@sne-journal.org; WWW: www.argesim.org, www.sne-journal.org Incorporated Austrian Society ZVR No 213056164 - EU VAT ID No ATU 72054279 Bank Account: ARGESIM, IBAN AT07 201118289115 0800, BIC GIBAATWWXXX, ERSTE BANK VIENNA 


\section{FOREWORD}

EUROSIM, the Federation of European Simulation Societies provides a European forum for regional and national simulation societies to promote the advancement of modelling and simulation in industry, research and development.

Under the EUROSIM umbrella, EUROSIM Member Societies and co-operating societies and groups organise conferences, produce publications on modelling and simulation, work in standardising or technical committees, etc. The scientific Journal SNE Simulation Notes Europe is the official scientific membership journal of EUROSIM.

Main event of EUROSIM is the EUROSIM CONGRESS, which is arranged every three years by a member society of EUROSIM.

EUROSIM 2019, the 10th EUROSIM Congress, is organised by CEA-SMSG, the Spanish Simulation Society, in La Rioja, Logroño, Spain, July 1-5, 2019. At EUROSIM 2019, the organizers provide a presentation forum for novel research and developments in continuous, discrete (event) and hybrid modelling, in simulation, in identification and optimization approaches, in big data analysis by simulation, etc. The congress welcomes contributions from both technical and non-technical areas, and from both M\&S methods and technologies and M\&S applications.

The Congress Proceedings will be electronically published as University of La Rioja Publication on DIALNET, with ISBN and individual DOIs. This EUROSIM 2019 Abstract Volume, ARGESIM Report no. 58, ISBN 978-3-901608-92-6 (ebook), compiles the abstracts of a part of the contributions to the congress, and is electronically available with DOI: 10.11128/arep.58 before the congress. Furthermore, selected contributions will be invited for post-conference publication in SNE Simulation Notes Europe.

EUROSIM 2019 is being held in the City of Logroño, Capital of La Rioja (Spain) very wellknown by the Rioja red wines. The main venue and the exhibition site is the University of La Rioja (UR), located on a modern campus in Logroño. The UR is the only public university in this small, quiet region in Northern Spain.

EUROSIM 2019 includes three days of work (Tuesday to Thursday) combined with cultural and social activities, a previous day of simulation courses and pre-reception (Monday), a day devoted to cultural and technical activities (Friday) - and announcement of the next congress EUROSIM 2022, Amsterdam, and finally, as an extension, the possibility of a trip (Saturday) to the festivities of San Fermines in Pamplona.

La Rioja offers three main points of interest to its visitors, especially to EUROSIM 2019 participants: the wine and the cellars, the monasteries, among which are Cañas, Valvanera, Santa Maria La Real, and of course the San Millán de la Cogolla monasteries (Suso and Yuso), cradle of the first words written in the Spanish language, included in UNESCO's World Heritage List in 1996, and the Santiago's Road, which for centuries has made constant and continuous the visit of pilgrims to the city, where they are always welcome.

Emilio Jiménez, Univ. La Rioja, EUROSIM President, Organizer EUROSIM Congress 2019 La Rioja

Juan Ignacio Latorre, Univ. Navarra,

Organizer EUROSIM Congress 2019 La Rioja 


\section{EUROSIM MEMBER SOCIETIES}

At present the following societies and groups are EUROSIM members:

ASIM - Arbeitsgemeinschaft Simulation (Austria, Germany, Switzerland)

CEA-SMSG - Spanish Modelling and Simulation Group Spain

CSSS - Czech and Slovak Simulation Society; Czech Republic, Slovak Republic

DBSS - Dutch Benelux Simulation Society; The Netherlands, Belgium,

KA-SIM - Kosovo Simulation Society; Kosov

LIOPHANT - LIOPHANT Simulation Club; Italy \& International

LSS - Latvian Simulation Society; Latvia

PSCS - Polish Society for Computer Simulation; Poland

MIMOS - Italian Modelling and Simulation Association, Italy

NSSM - Russian National Simulation Society; Russian Federation

SIMS - Simulation Society of Scandinavia; Denmark, Finland, Norway, Sweden

SLOSIM - Slovenian Simulation Society; Slovenia

UKSIM - United Kingdom Simulation Society; UK, Ireland

ROMSIM - Romanian Soc. for Modelling and Simulation; Romania, Observer Member

ALBSIM - Albanian Simulation Society; Albania; Candidate Member

Societies in Re-Organisation:

CROSSIM - Croatian Society for Simulation Modeling; Croatia

FRANCOSIM - Société Francophone de Simulation; France, Belgium

HSS - Hungarian Simulation Society; Hungary

ISCS - Italian Society for Computer Simulation; Italy 


\section{CONTENTS}

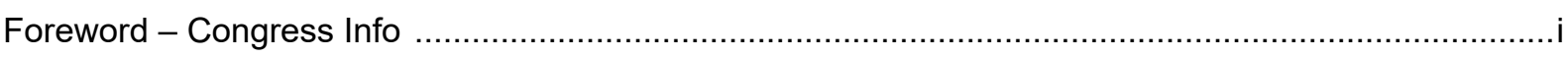

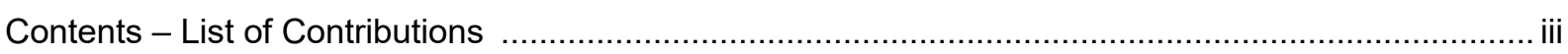

\section{Submitted Contributions}

A Combined Weighting Method Based on Hierarchical Clustering

Xiaofeng Hu, Wei Li, Ping Ma, Ming Yang ....

Post-Harvest Olive-Table Characterisation by Means of Image Analysis

Arturo Aquino, Juan Manuel Ponce, Borja Millan, Diego Tejada-Guzmán, José Manuel Andújar ......... 2

New Risks and Opportunities for Companies \& Engineers in Cyber and Hybrid Scenarios:

Intelligent Systems \& Soft Computing to Reduce Vulnerabilities

Agostino G. Bruzzone, Marina Massei, Kirill Sinelshchikov .

Influence of process parameters on the morphology of additive manufacturing beads using

WAAM technology in high deposition rate processes

Iván Monzón, Jose Antonio Dieste, Alberto Laguia, Carlos Javierre, Daniel Elduque.

Influence of process parameters on the morphology of additive manufacturing beads using

thermoset extrusion technology in high deposition rate processes

Alberto Laguia, Jose Antonio Dieste, Iván Monzón, Carlos Javierre, Daniel Elduque.

Automated generation and selection of the electronic circuit black-box model inputs

Vladimir Ceperic, Alma Trazivuk

Simulation of Hydrate Plug Prevention in Natural Gas Pipeline from Bohai Bay to Onshore

Facilities in China

Solomon Aforkoghene Aromada, Bjørn Kvamme

Production of Methane from Hydrate and $\mathrm{CO}_{2}$ Zero-Emission Concept

Solomon Aforkoghene Aromada, Bjørn Kvamme....

Modelling of Methane Hydrate Formation and Dissociation using Residual Thermodynamics

Solomon Aforkoghene Aromada, Bjørn Kvamme ....

A methodology for improving the PI controller of a wind turbine on a semi-submersible offshore platform: development and evaluation of an anti windup algorithm $P$. Zambrana-Lopez, J.J.

Fernandez-Lozano, J. Fernandez-Quijano, Pedro M. Mayorga Rubio, A.J. Garcia-Cerezo

Estimating the flight departure duration from push-back to take-off

E.M. de Mol, M. Mitici, F.F. Herrema, and B. Desart

Robust Simulation of Stream-Dominated Thermo-Fluid Systems: From Unidirectional to

Bidirectional Applications

Dirk Zimmer

A socio-technical holistic ABM simulation framework to assess ATC performance variability Gabriella Gigante, Domenico Pascarella, Marta Sánchez Cidoncha, Miquel Angel Piera, Juan José Ramos, Gabriella Duca, Mario Ciaburri, Luiz Manuel Braga, Jose Luis Munoz-Gamarra.

Motion Detection in Videos of Coherence Matrices in order to detect Consciousness States in CLIS-patients - an Approach

V. S. Adama, A. Blankenburg, C. Ernst, R. Kummer, S. Murugaboopathy, and M. Bogdan ..

Cable suspended load UAV hybrid automata modelling and neuro-control

Jesús Enrique Sierra and Matilde Santos....

Wildfire spreading simulator using Fast Marching algorithm

Juan Carballeira, Carolina Nicolás, Santiago Garrido, and Luis Moreno. 16 
Multi-objective optimization based on decomposition of weight vectors generated by Latin Hypercube

Du Zhiwen, Chao Tao, Ma Ping and Yang Ming

Dimensional Behavior of recycled Polypropilene

Isabel Clavería, Daniel Elduque, Carlos Javierre, Carmelo Pina, Raquel Acero.

Extendable Hybrid approach to detect conscious states in a CLIS patient using machine learning

V. S. Adama, S.-J. Wu, N. Nicolaou, and M. Bogdan

Machine learning and the digital era from a Process Systems Engineering perspective

José Luis Pitarch and César de Prada.

Analyzing the Effects of Geometrical and Particle Size Uncertainty in Circulating Fluidized

Beds using CPFD Simulation

Janitha C. Bandara, Britt M.E. Moldestad, Marianne S. Eikeland.

Control-Oriented Modelling and Simulation - the Impact to the INMOTION Project

Borut Zupančič, Gašper Mušič, Maja Atanasijević-Kunc, Sašo Blažič, Milan Simčič

Traffic Jam Assist Simulation and Analysis

J. Echeto, M. Santos and M. G. Romana...

Optimized Balance of Plant for a medium-size PEM electrolyzer. Design, Modelling and Control

Caparrós J.J., Vivas F.J., Segura F. and Andújar J.M.

Machine Learning Perspectives in Concentrating Solar Thermal Technology

Javier Bonilla, Jose A. Carballo, Manuel Berenguel, Jesús Fernández-Reche, Loreto Valenzuela..... 25

An Adaptable Full-Scale Aircraft Cabin Simulator for Human-in-the-Loop Simulations

Mario Kallenbach, Stephan Kocks, and Thomas Feuerle.

Quick, Stat!: A Statistical Analysis of the Quick, Draw! Dataset

Raul Fernandez-Fernandez, Juan G. Victores, David Estevez, and Carlos Balaguer

Role of human resources on TQM benefits

Jorge Luis García Alcaraz, Juan Carlos Sáenz Diez-Muro and Emilio Jiménez Macías.

The simulation modeling as the part of grid methods of uniform probing for the dynamic stochastic systems investigation

G. M. Antonova.

Using Deep Learning to classifier emotions in images in the tourism field

Diaz S., Torres, J.M., and Aguilar, R.M.....

Identification and Validation of a Barge Floating Offshore Wind Turbine Model with Optimized

Tuned Mass Damper

D. Villoslada, M. Santos and M. Tomás-Rodríguez

Analytical design and validation of OWC chamber device models by means of real-time experimental data

Aitor J. Garrido, Erlantz Otaola, Manuel De la Sen and Izaskun Garrido

Guarantying consistency of spatio-temporal regions that solve air traffic conflicts

Thimjo Koca and Miquel Angel Piera ....

Industrial AGV holistic modelling approach

Jesús Enrique Sierra

Towards Clothes Hanging via Cloth Simulation and Deep Convolutional Networks

David Estevez, Juan G. Victores, Raul Fernandez-Fernandez, and Carlos Balaguer

Floating Offshore Wind Turbines Oscillations Damping

M. Tomas-Rodriguez, K. Feroz, and M. Santos. 36 
Methodology to achieve convergence in a rigorous dynamic model of a superfractionator Erika Oliveira-Silva, Cesar de Prada.

Encoder-Decoder LSTM for predicting household electricity consumption using public data Aguilar, R.M., Hamilton, A., and Cabrera, P.

Application of CAE to model and simulate wheel-ground contact in railway vehicle

Julian Malaka.

Review of neural modelling on cardiovascular rehabilitation active processes by using

cycloergometers

Gorka Miñano, Mikel Larrea, and Eloy Irigoyen

Advanced machine learning in recursive data-based modelling

Esko K. Juuso.

Simulation of Regular Waves on Floating Wind Turbines: Preliminary Analysis

Segundo Esteban, Rafael Lopez, María Guijarro, and Matilde Santos

A survey of damage control methods for wind turbines based on sensors: a first approach

M. Guijarro, S. Esteban and M. Santos....

Sequence-to-Sequence Natural Language to Humanoid Robot Sign Language

Jennifer J. Gago, Valentina Vasco, Bartek Łukawski, Ugo Pattacini, Vadim Tikhanoff, Juan G.

Victores, and Carlos Balaguer.

pyEff: New tool for code efficiency measurement

Guillermo Calvo Álvarez, Jesús Enrique Sierra

Simulation processes for on-board state estimation in a small UAV environment

Marsel Omeri, Marko Radanovic, Ernesto Emmanuel Santana Cruz, Romualdo Moreno Ortiz

Adapted Laboratory for Mobile Robotics Teaching and its Application to Coordinated

Control of Robots

David Gallarta Sáenz, Pablo Álvarez Benito, Javier Rico-Azagra and Montserrat Gil-Martínez

Genetic Algorithms in the domain of personalized nutrition

Petri Heinonen and Esko K. Juuso.....

Python-Based eSES/MB Framework: Model Specification and Automatic Model Generation for Multiple Simulators

Hendrik Folkerts, Christina Deatcu, and Thorsten Pawletta

Military Operational Decision Maker based on Blocks feedback, using uncertainty techniques

G. Minguela Castro, Carlos Cerrada, J.A. Cerrada.

Neural Model Applied to a Conversational Agent in a Closed Domain

M. Rodriguez, F. Matia, P. San Segundo

Hybrid Models and Digital Twins for Condition Monitoring: HVAC System for Railway

Antonio Gálvez, Jokin Rubio, Dammika Severiratne, Asier González, Alberto Jimenez,

Unai Martinez-de-Estarrona, Diego Galar and Esko Juuso

Hydraulic Press Commissioning Cost Reductions via Machine Learning Solutions

Ignacio Trojaola, Iker Elorza, Eloy Irigoyen, and Aron Pujana.

Preliminary design of modular electrolyzer for photovoltaic energy utilization in Smart Micro-Grids

Julián Seco Martín, Antonio José Calderón Godoy, Isaías González Pérez,

Manuel Calderón Godoy......

Human behavior modeling in crowded scenarios by reference nets

Juan-Ignacio Latorre-Biel, Eduardo Martínez Cámara, Julio Blanco Fernández,

Mercedes Pérez de la Parte, Juan Carlos Sáenz-Díez, Emilio Jiménez Macías. 
Blockchain techniques applied to Petri Net state space. An approach to ensure security in Petri Net state evolution

Íñigo Leon, Juan Ignacio Latorre, Emilio Jiménez

Wine Aging in Reused Oak Barrels Sanitized with Carbon Dioxide

Francisco J. Flor, Mercedes Pérez, Emilio Jiménez, Eduardo Martínez, Julio Blanco

Carbon dioxide as a new oak barrel cleaning process. Influences on the volatile compounds

of oak-wood

Francisco J. Flor, Mercedes Pérez, Emilio Jiménez, Eduardo Martínez, and Julio Blanco 58

\section{Invited Technical Contributions}

Review on Monte Carlo Simulation Stopping Rules: How Many Samples Are Really Enough?

Martin Bicher, Matthias Wastian, Dominik Brunmeir, Matthias Rößler, and Niki Popper.

Modelling landside logistic operations of a Megahub airport with discrete-event simulation

Rodrigo Romero-Silva, Miguel Mujica Mota

\section{Invited Main Contributions}

Formal Methods and Simulation: Cooperation makes strength Manuel Silva

Renewable sources-based smart micro grids with hydrogen as backup: modeling, control, implementation and management. A real case

José Manuel Andújar.

Nature, Features and Properties of Developments in Modelling and Simulation from A -Alternative to Z - Zippy

Felix Breitenecker. 


\title{
A Combined Weighting Method Based on Hierarchical Clustering
}

\author{
Xiaofeng $\mathrm{Hu}$, Wei Li , Ping Ma, Ming Yang \\ Control and Simulation Center, Harbin Institute of Technology, 150001 Harbin , China \\ 18845150705@163.com, frank@hit.edu.cn, pingma@hit.edu.cn, \\ myang@hit.edu.cn
}

Abstract. Index weight determination plays an important role in performance evaluation of simulation system and determines the accuracy of evaluation results. According to the analysis of the characteristics of traditional weighting methods, this paper proposes a combined weighting method based on hierarchical clustering. Consistency test is used to eliminate singularities in subjective weights, and a programming function is constructed to obtain the optimal subjective weights. Hierarchical clustering is used to sort the elements of the optimal subjective weight vector, and the importance order of the indexes is obtained. An optimization model of combined weights is established, and the order information is added to the constraints of the optimization model to minimize the overall deviation between the ideal combined weight and all objective weights and the optimal combination weight. The combined weights are obtained by least square method. Finally, an example is given to verify the rationality of this method.

Keywords: performance evaluation, combined weighting method, consistency test, hierarchical clustering, optimization model. 


\title{
Post-Harvest Olive-Table Characterisation by Means of Image Analysis
}

\author{
Arturo Aquino, Juan Manuel Ponce, Borja Millan, Diego Tejada-Guzmán, José \\ Manuel Andújar \\ Department of Electronic Engineering, Computer Systems and Automatics, University of \\ Huelva, Carretera Huelva-Palos, s/n, 21810 Palos de la Frontera, Spain \\ \{arturo. aquino, jmponce.real, borja.millan, diego.tejada, \\ andujar\}@di esia.uhu.es
}

Abstract. Post-harvest table-olive classification according to size and mass is especially important when pursuing high-quality outcomes. This paper presents a new methodology aimed at supporting accurate automatic olive-fruit grading by using artificial vision. To this end, 3,600 olive-fruit samples from nine varieties were imaged using an ad-hoc designed capturing chamber; the individuals were randomly distributed on scene. Then, an image analysis algorithm, based on mathematical morphology, was designed to individually segment olives and extract descriptive features to estimate their major and minor axes, and their mass. Next, by linearly correlating the data obtained by image analysis and the corresponding reference measurements, models for estimating the three features were computed. Then, the models were tested on 2,700 external validation samples, giving relative errors below $0.80 \%$ and $1.05 \%$ for the estimation of the major and minor axis length for all varieties, respectively. In the case of estimating olive-fruit mass, the models provided relative errors never exceeding $1.01 \%$. The ability of the developed algorithm to individually segment olives stochastically positioned, along with the low error rates of around $1 \%$ reported by the estimation models for the three features, makes the methodology a promising alternative to be integrated in a new generation of improved and noninvasive olive classification machines.

Keywords: Computer Vision, Feature Modelling, Food Industry, Fruit Grading, Image Analysis, Olive Fruit. 


\title{
New Risks and Opportunities for Companies \& Engineers in Cyber and Hybrid Scenarios: Intelligent Systems \& Soft Computing to Reduce Vulnerabilities
}

\author{
Agostino G. Bruzzone, Marina Massei, Kirill Sinelshchikov \\ STRATEGOS, University of Genoa, Italy \\ \{agostino, massei\}@itim.unige.it, kirill@simulationteam.com
}

\begin{abstract}
This paper addresses the need to develop a combined approach based on Simulation, Data Analytics and AI to reduce Vulnerabilities in Infrastructure and complex Systems. By this scientific approach it is possible to address Security and to support development of new Strategies. Indeed the evolving scenario introducing new technologies and increasing interconnectivity provides very interesting opportunities as well as new threats that need to be investigated by this approach that is currently defined as Strategic Engineering. The use of AI and Soft Computing combined with Simulation based on Big Data provides great opportunities in this sense and the authors propose some case study to demonstrate how new generation engineers and scientists will have to apply Strategic Engineering to Hybrid Scenarios to improve Resilience, Safety and Security.
\end{abstract}




\title{
Influence of process parameters on the morphology of additive manufacturing beads using WAAM technology in high deposition rate processes
}

\author{
Iván Monzón ${ }^{1}$ [0000-0002-4549-4716](घivan.monzon@aitiip.com), Jose Antonio Dieste 2[0000-0001-7178- \\ ${ }^{4285]}$, Alberto Laguia ${ }^{3[0000-0002-0144-4143]}$, Carlos Javierre ${ }^{40000-0002-8008-4819]}$, Daniel \\ Elduque 5 [0000-0001-9137-3387] \\ ${ }^{1}$ R\&D Department, Fundación AITIIP, Calle Romero 12, 50720 Zaragoza, Spain \\ ivan.monzon@aitiip.com \\ ${ }^{2}$ R\&D Department, Fundación AITIIP, Calle Romero 12, 50720 Zaragoza, Spain \\ joseantonio.diestedaitiip.com \\ ${ }^{3}$ R\&D Department, Fundación AITIIP, Calle Romero 12, 50720 Zaragoza, Spain \\ alberto.laguia@aitiip.com \\ ${ }^{4}$ Department of Mechanical Engineering, University of Zaragoza, Spain \\ carlos.javierreeunizar.es \\ ${ }^{5}$ Department of Mechanical Engineering, University of Zaragoza, Spain \\ delduque@unizar.es
}

\begin{abstract}
Metal additive manufacturing is a term that encompasses cutting edge technologies allowing to build new parts, tools and products layer by layer, adding material with a controlled deposition method and in contrast with current subtractive technologies. Researches, technologies and even machines have been developed during the latest years. On some occasions, this has resulted in commercial systems able to print metal parts directly from a computer assisted design, but still some problems remain when it comes to processing time, material price, material quality, and the own quality of the built structures. All these keep Metal additive manufacturing from being widely incorporated in industrial processes. This paper proposes to research Gas Metal Arc Welding processes and technologies for metal additive manufacturing and determining the influence parameters $(\mathrm{AC} / \mathrm{DC} /$ pulsed, current, voltage, wire speed, velocity) in the printed beam geometry. It will be developed a battery of controlled tests that allows to obtain a mathematical model or a regression model that allows to model the process.
\end{abstract}

Keywords: MAM, WAAM, Additive Manufacturing. 


\title{
Influence of process parameters on the morphology of additive manufacturing beads using thermoset extrusion technology in high deposition rate processes.
}

\author{
Alberto Laguia ${ }^{1[0000-0002-0144-4143](Ð a l b e r t o . l a g u i a @ a i t i i p . c o m) ~}$, Jose Antonio Dieste 2[0000-0001- \\ 7178-4285], Iván Monzón ${ }^{3[0000-0002-4549-4716]}$, Carlos Javierre ${ }^{40000-0002-8008-4819]}$, Daniel \\ Elduque [0000-0001-9137-3387] $^{2}$ \\ ${ }^{1}$ R\&D Department, Fundación AITIIP, Calle Romero 12, 50720 Zaragoza, Spain \\ alberto.laguia@aitiip.com \\ ${ }^{2}$ R\&D Department, Fundación AITIIP, Calle Romero 12, 50720 Zaragoza, Spain \\ joseantonio.diestedaitiip.com \\ ${ }^{3}$ R\&D Department, Fundación AITIIP, Calle Romero 12, 50720 Zaragoza, Spain \\ ivan.monzon@aitiip.com \\ ${ }^{4}$ Department of Mechanical Engineering, University of Zaragoza, Spain \\ carlos.javierredunizar.es \\ ${ }^{5}$ Department of Mechanical Engineering, University of Zaragoza, Spain \\ delduque@unizar.es
}

Abstract. Material extrusion is the most industrially demanded additive manufacturing group of technologies. Fused Deposition Modeling is by far the system that covers the largest market share. However, it has great limitations, mainly related to efficiency and long printing time, which complicate its industrial implementation. This paper presents a novel extrusion-based AM technology, based in thermoset material printing, that permits deposition rates much higher than FDM, that could accelerate in a medium-term period, the industrial adoption of polymer AM. The research shows the geometrical definition of the printed beads, the layer-based packaging methodology, to develop a mathematical model, that can be used for the CAD simulation of the scheduled printing AM geometry, within this novel AM technology approach. This model has been validated by the use of empirical experiments, and scaled up in a large deposition rate, and high-volume robotic printing environment.

Keywords. Additive Manufacturing (AM), Material extrusion, PUR. 


\title{
Automated generation and selection of the electronic circuit black-box model inputs
}

\author{
Vladimir Ceperic ${ }^{1[0000-0002-7059-2369](\square)}$ and Alma Trazivuk ${ }^{2 \text { [0000-0002-1995-3026] }}$ \\ 1 University of Zagreb, Faculty of Electrical Engineering and Computing, Unska 3, 10000 \\ Zagreb, Croatia \\ vladimir.cepericefer.hr \\ 2 University of Zagreb, Faculty of Electrical Engineering and Computing, Unska 3, 10000 \\ Zagreb, Croatia \\ alma.trazivukefer.hr
}

\begin{abstract}
This paper introduces the method for the automated generation and selection of the model inputs and training data points for the black-box modelling of electronic circuits. Firstly, the challenges of the use and implementation of the automated generation and selection of the model inputs and training data points are described. Then, a brief overview of the methods for stimulating the circuit in the process of obtaining an optimal training data set is given. Afterwards, the pre-processing of the model inputs and outputs is discussed. A new method for the selection and ranking of the model inputs and the training data points is presented. The proposed algorithm is suitable for selection of the model inputs and training data points for the black-box modelling of electronic circuits. Finally, a circuit example of the application of the proposed algorithm is presented. At the end of this paper, a summary that lists the contributions of the performed research is given.
\end{abstract}

Keywords: behavioural modelling, automated model generation, electronic circuit black-box model. 


\title{
Simulation of Hydrate Plug Prevention in Natural Gas Pipeline from Bohai Bay to Onshore Facilities in China
}

\section{EUROSIM 2019}

\author{
Solomon Aforkoghene Aromada ${ }^{1[\mathrm{ORCD}](\square)}$, Bjørn Kvamme ${ }^{2[\mathrm{ORCD}]}$ \\ ${ }^{1}$ Department of Physics and Technology, University of Bergen, Allegaten 55, 5007 Bergen, \\ Norway \\ Solomon.Aromadalstudent.uib.no
}

${ }^{2}$ Strategic Carbon LLC, Vestre Holbergsallmenningen 17, 5011 Bergen, Norway bkvammedstrategic-carbonllc.com

\begin{abstract}
.
Natural gas hydrates occasionally plug the $58 \mathrm{~km}$ subsea pipeline that transports natural gas from Platform QK18-1 in southwest of Bohai Bay to the processing facility onshore in Northeast China. This is because it is a wet gas subsea pipeline that operates at high pressures and low temperatures, which are the conditions that are appropriate for hydrate formation to occur. In this study, we proposed that the best way to prevent the occasional plugging of the pipeline is to rightly evaluate the upper limit of water that can be permitted in the bulk gas and dehydrate the gas accordingly before transport. Current industrial techniques are mainly based on water dewpoint evaluations. In our recent work we have proposed another approach that considers the impact of the rust (Hematite) on the internal walls of pipelines. These two methods have been used for this study. The results of the method of adsorption of water onto rusty (Hematite) surfaces suggest that the current approach (dewpoint method) overestimates the safe-limit of water about 18 to 19 times higher. Thus, the risk of hydrate formation may still exist if the dewpoint method is used as basis for drying the gas. Sensitivity analysis shows the influence of pressure on the upper limit of water- the higher the pressure the lower the maximum concentration of water that is safe to accompany the gas. Our calculations were done using a FORTRAN code that utilize thermodynamic data from molecular dynamics simulation.
\end{abstract}

Keywords: Natural gas hydrate, simulation, rust. 


\title{
Production of Methane from Hydrate and $\mathrm{CO}_{2}$ Zero- Emission Concept
}

\section{EUROSIM 2019}

\author{
Solomon Aforkoghene Aromada ${ }^{1[O R A D]}(\square)$, Bjørn Kvamme ${ }^{2[O R A D]}$ \\ ${ }^{1}$ Department of Physics and Technology, University of Bergen, Allegaten 55, 5007 Bergen, \\ Norway \\ Solomon. Aromadaestudent.uib.no \\ ${ }^{2}$ Strategic Carbon LLC, Vestre Holbergsallmenningen 17, 5011 Bergen, Norway \\ bkvammedstrategic-carbonllc.com
}

\begin{abstract}
.
We have evaluated enthalpies of formation, or dissociation, for hydrates of $\mathrm{CO}_{2}$ and $\mathrm{CH}_{4}$. The exothermic heat released when a $\mathrm{CO}_{2}$ hydrate is formed could be $9-10 \mathrm{~kJ} / \mathrm{mol}$ of guest molecule more than the heat required to dissociate a $\mathrm{CH}_{4}$ hydrate to methane gas and liquid water. The implication is that the heat released is available for dissociating the surrounding $\mathrm{CH}_{4}$ hydrate to $\mathrm{CH}_{4}$ gas and liquid water. In addition to the free pore water additional free water will become available for new $\mathrm{CO}_{2}$ hydrate to form in place of the original $\mathrm{CH}_{4}$ hydrate. The released $\mathrm{CH}_{4}$ will migrate upwards due to buoyancy. The pressure-temperature projection is not what is essential to replace in situ methane hydrate with carbon dioxide. The difference in free energy of the two hydrates $\left(\mathrm{CO}_{2}\right.$ and $\mathrm{CH}_{4}$ hydrates $)$ and the heat of crystallization of $\mathrm{CO}_{2}$ hydrate relative to the heat of dissociation (or formation) of the $\mathrm{CH}_{4}$ hydrate is what is vital. This is based on the combined first and second laws of thermodynamics. Carbon dioxide hydrate is thermodynamically more stable than methane hydrate in respect of free energy. The free energy of $\mathrm{CO}_{2}$ hydrate may be $1.8-2.0 \mathrm{~kJ} / \mathrm{mol}$ lower than that of $\mathrm{CH}_{4}$ hydrate.
\end{abstract}

Keywords: Hydrate, CO2, methane. 


\title{
Modelling of Methane Hydrate Formation and Dissociation using Residual Thermodynamics
}

\section{EUROSIM 2019}

\author{
Solomon Aforkoghene Aromada $\left.{ }^{1[O R C I D](} \boxminus\right)$, Bjørn Kvamme ${ }^{2[O R C I D]}$ \\ ${ }^{1}$ Department of Physics and Technology, University of Bergen, Allegaten 55, 5007 Bergen, \\ Norway \\ Solomon. Aromadaestudent.uib.no \\ 2 Strategic Carbon LLC, Vestre Holbergsallmenningen 17, 5011 Bergen, Norway \\ bkvammedstrategic-carbonllc.com
}

\begin{abstract}
This summary should contain between 150 to 250 words.
The available experimental data in literature for enthalpies of hydrate formation and dissociation are limited and often lacks relevant information required for interpretation. Commonly missing information include hydrate composition, hydration number, temperature and/or pressure data, and degree of super heating during dissociation of hydrate. Clausius-Clapeyron equations used with measured or calculated hydrate formation pressure-temperature equilibrium data is the simplest indirect methods used for evaluating enthalpy change involve in phase transition during hydrate formation or dissociation. However, this approach involved over-simplifications. These over simplifications make all the data based on Clausius-Clapeyron to be unreliable. And old data using Clapeyron do not have appropriate volume corrections. We therefore propose a thermodynamic scheme (residual thermodynamics approach) without these limitations. This method is based on residual thermodynamics for all properties like equilibrium (pressure-temperature) curves, free energy change as thermodynamic driving force in kinetic theories and enthalpies of hydrate formation and dissociation.
\end{abstract}

Keywords: Residual thermodynamics, hydrate, dissociation. 


\title{
A methodology for improving the PI controller of a wind turbine on a semi-submersible offshore platform: development and evaluation of an anti windup algorithm
}

\author{
P. Zambrana-Lopez ${ }^{1[\mathrm{OR} A D]}$, J.J. Fernandez-Lozano ${ }^{2[\mathrm{ORAD}](\square)}$, J. Fernandez- \\ Quijano $^{2[\mathrm{ORAD}]}$, Pedro M. Mayorga Rubio ${ }^{2[\mathrm{ORAD}]}$, A.J. Garcia-Cerezo ${ }^{3 \text { [ORAD] }}$ \\ ${ }^{1}$ Departamento de Ingeniería de Sistemas y Automática, Universidad de Málaga, Av. de \\ Cervantes, 2, 29016 Málaga, Spain \\ jfleuma.es \\ ${ }^{2}$ EnerOcean S.L., Bulevar Louis Pasteur 5, Of.321. Málaga, España
}

\begin{abstract}
The exploitation of sea wind energy is restricted by the suitable sites in shallow waters. Offshore semi-submersible platforms, which also allow the integration of other components like wave energy converters, appear as an option. Yet, the interactions of the wind turbine and the platform movements increase the system's controller complexity. Using PI control schemes is a robust alternative to take full account of the said interactions and to improve energy capture efficiency. Nevertheless, a simulation model that includes those effects beforehand is required, so that controller behavior can be evaluated together with its influence in the performance of the system. This paper presents a methodology and its application to enhance controllers for wind turbines in semi-submersible offshore platforms, resulting in an improvement for the PI reference controller. The methodology is based on the creation of an integrated simulation tool, by combining stand-alone simulation software, together with defining three performance indexes to describe the performance of the control system in the overall platform behavior regarding key aspects of its exploitation, like structural loads or efficiency in energy generation. The proposed methodology is used to develop and test two controllers (the baseline PI and an improved PI), evaluating their performance through the simulation results together with the proposed performance indexes.
\end{abstract}

Keywords: Floating Offshore Wind Turbines (FOW), Modelling and control of FOW, Renewable energy systems, PID control. 


\title{
Estimating the flight departure duration from push-back to take-off
}

\author{
E.M. de $\mathrm{Mol}^{1}$, M. Mitici ${ }^{1}$, F.F. Herrema ${ }^{1}$, and B. Desart ${ }^{2}$ \\ 1 Faculty of Aerospace Engineering, Delft University of Technology, Kluyverweg 1, 2629 \\ HS Delft, The Netherlands \\ m.a.mitici@tudelft.nI \\ 2 EUROCONTROL, Rue de la Fusée 96, Brussels 1130, Belgium \\ bruno.desarteeurocontrol.int
}

\begin{abstract}
In this paper we analyse the departure time from push-back to take-off at an European airport. We consider a system of two runways, and analyse the most frequently used configuration during peak hours, which allows for departures only from one runway and mixed-mode operations for the other runway. We consider the flight departure process to be consisting of three distinct phases: the pushback phase, the taxi phase and the runway utilisation phase. We model the runway utilisation by means of a G/G/1 queuing model. The other phases are modelled based on a data-driven analysis of the flight profiles at the airport. Lastly, we estimate the entire duration of a flight departure from push-back to take-off by means of Monte Carlo simulation. Our proposed approach estimates well the flight departure duration when taking into account the operations on both runways, with a mean error of 0.7 minutes.
\end{abstract}

Keywords: Monte Carlo simulation, uncertainty, departure process. 


\title{
Robust Simulation of Stream-Dominated Thermo-Fluid Systems: From Unidirectional to Bidirectional Applications
}

\author{
Dirk Zimmer \\ ${ }^{1}$ DLR German Aerospace Center, Insitute of System Dynamics and Control, \\ Münchener Strasse 20, 82234 Oberpfaffenhofen, Germany, \\ dirk.zimmer@dlr.de
}

\begin{abstract}
A new robust and efficient formulation for stream-dominated thermal fluid systems has been developed recently. So far only applications of this formulation for systems with known flow direction have been presented. This paper extends the underlying methodology for bidirectional fluid streams that can handle flow reversal and presents the example of an aircraft bleed-system.
\end{abstract}

Keywords: Thermal fluid systems, Thermal process systems, Environmental control systems, Aircraft systems, Object-Oriented Modeling 


\title{
A socio-technical holistic ABM simulation framework to assess ATC performance variability
}

\author{
Understanding hidden inter-relationships between human actors and its supporting tools to \\ improve ATM performance
}

\author{
Gabriella Gigante, Domenico \\ Pascarella
}

CIRA Italian Aerospace Research Centre

Capua, Italy

g.gigante@cira.it,

d.pascarella@cira.it

Gabriella Duca, Mario Ciaburri

ISSNOVA Institute for Sustainable

Society and Innovation

Naples, Italy

duca@issnova.eu

ciaburri@issnova.eu
Marta Sánchez Cidoncha

CRIDA Centro De Referencia

Investigacion Desarrollo e

Innovacion

Madrid, Spain

mscidoncha@e-crida.enaire.es

Luiz Manuel Braga

PEDECE Projectos, Empreendimentos, Desenvolvimento e Equipamentos Científicos e De Engenharia

Lisboa, Portugal

luis.campos@tecnico.ulisboa.pt

\author{
Miquel Angel Piera \\ Juan José Ramos \\ Universitat Autònoma De Barcelona \\ Barcelona, Spain \\ miquelangel.piera@uab.cat \\ juanjose.ramos@uab.es
}

Jose Luis Munoz-Gamarra ASLOGIC

Barcelona, Spain

jlmunoz@aslogic.es

\begin{abstract}
The mesh of information that influence a human actor in its decision-making process is difficult to formalize and more difficult to validate. Stochastic approaches to represent human actors provides a fast modelling approach that can be statistically validated, however, considering the importance in ATM that the combination of independently safe procedures could derive into an unsafe one, better modelling approaches are needed to support a deeper understanding of the causes of a poor performance and the propagation mechanisms that spark emergent behavior and its effects. There is a lack of tools to better understand the impact of the time variability in the tasks assigned to human actors (ie. ATCo's, Pilots, FOC's) and the performance variability on the technological component functionalities in the ATM performance at system level. In this paper it is presented an agent based modeling framework to identify those factors that affects the performance of the ATM functionalities considering different socio-technical operational conditions. As a result, it is expected the design of new mechanisms to enhance the robustness of the actor-component interdependencies by means of adapting some component functionalities, ATC tasks or introducing changes in well accepted ATM procedures.
\end{abstract}

Air Traffic Controller Attributes, Socio-Technical Systems, Influence Variables, Agent Based Modelling, Functional Resonance Analysis Method, 


\title{
Motion Detection in Videos of Coherence Matrices in order to detect Consciousness States in CLIS-patients - an Approach
}

\author{
V. S. Adama $\left.{ }^{(}\right)$, A. Blankenburg, C. Ernst, R. Kummer, S. Murugaboopathy, and \\ M. Bogdan \\ University of Leipzig, Augustusplatz 10, 04109 Leipzig, Germany \\ adama | bogdan einformatik.uni-leipzig.de
}

\begin{abstract}
Eye movements can be used as a means to communicate with locked-in patients. Despite being aware of themselves and their environment, these patients are unable to perform any voluntary movement except from the eyes. As they transition to a complete locked-in state, there is no residual eye movement left. At that point, even though they manifest "normal" cognitive functions, it becomes difficult to communicate with them, much less to know at which point they are indeed conscious and awake. In order to uncover states of consciousness in such patients, the evolution of coherence matrices across time of all frequency bands were analyzed. To do so, the coherence matrices were combined into a video in a chronological order manner. During visual inspection, changes of directions of the brain waves in some frequency bands were observed. This paper investigates the usage of autoencoder with a directional neuron and optical flow to detect these direction changes during different states of consciousness in order to differentiate them, using coherence matrices.
\end{abstract}

Keywords: Artificial Neural Networks, Autoencoder, Coherency, Optical Flow. 


\title{
Cable suspended load UAV hybrid automata modelling and neuro-control
}

\author{
Jesús Enrique Sierra ${ }^{(\varpi)}$ and Matilde $\operatorname{Santos}^{2}$ \\ ${ }^{1}$ Department of Civil Engineering, University of Burgos, 09006 Burgos, Spain \\ jesierra@ubu.es \\ ${ }^{2}$ Computer Science Faculty, Complutense University of Madrid, 28040 Madrid, Spain \\ msantos@ucm.es
}

\begin{abstract}
In this work a new intelligent control strategy based on neural networks is proposed to cope with an external disturbance that can affect unmanned aerial vehicles (UAVs) dynamics in many applications: the cable suspended load. First the model of quadrotor with a cable suspended load is obtained by the hybrid automata formalism and its directed graph representation is described. The Lagrange-D'Alembert principle of minimal action is used to obtain the differential equations. Then a novel neural control strategy is proposed. The controller is based on feedback linearization combined with an artificial neural network that identifies the disturbance introduced by the cable suspended load. The controller is able to stabilize the quadrotor without any information about neither the position of the load nor the tension in the cable. This proposal can be especially useful in applications where this information is not available. Simulation results show how the on-line learning of the artificial network increases the robustness of the controller, reducing the effects of the cable suspended load in the quadrotor dynamics.
\end{abstract}

Keywords: Modelling, simulation, hybrid automata, neural control, quadrotor, suspended load. 


\title{
Wildfire spreading simulator using Fast Marching algorithm
}

\author{
Juan Carballeira $\left.{ }^{(}\right)$, Carolina Nicolás, Santiago Garrido, and Luis Moreno \\ Department of Systems and Automation, Carlos III University of Madrid, 28911 Madrid, \\ Spain \\ jcarballepa.uc3m.es
}

\begin{abstract}
Programs that can predict wildfire behavior are a very useful tool in terms of extinguishing these fires more effectively. State of the art wildfire simulators present some drawbacks such as not being sufficiently user-friendly, being expensive, requiring great computational power or having poor graphical representation. This paper presents a prototype wildfire simulation app that uses Fast Marching (FM) as its core algorithm. The wildfire app is developed as a Matlab GUI. Said application shows the shape of the fire front at a given moment in time in a 3D map of the terrain affected by the fire. Any real life maps can be loaded to the application for wildfire prediction. The user can choose to vary parameters such as starting (ignition) and ending points, wind direction and speed and propagation time, and see its effect on fire propagation. Interface response to each change in the input is very fast, therefore proving the efficiency of the algorithm. Although a prototype, the wildfire basic app is superior to some state of the art simulators regarding certain important features. It can be concluded that Fast Marching is a valid core algorithm for a fire simulator. The way the app is programmed in Matlab confers it flexibility, enabling further specific changes that make it truly competitive against currently used wildfire simulators.
\end{abstract}

Keywords: Fast Marching, fire prediction, fire spreading simulation, Matlab GUI, planning algorithm 


\title{
Multi-objective optimization based on decomposition of weight vectors generated by Latin Hypercube
}

\author{
Du Zhiwen ${ }^{1}$, Chao Tao ${ }^{2}$, Ma Ping $^{3}$ and Yang Ming*4(凶) \\ ${ }^{1}$ Control and Simulation center, Harbin Institute of Technology, 150080 Harbin, China \\ 18813058522@163.com \\ ${ }^{2}$ Control and Simulation center, Harbin Institute of Technology, 150080 Harbin, China \\ chaotao2000@163.com \\ ${ }^{3}$ Control and Simulation center, Harbin Institute of Technology, 150080 Harbin, China \\ pingma@hit.edu.cn \\ ${ }^{4}$ Control and Simulation center, Harbin Institute of Technology, 150080 Harbin, China \\ myang@hit.edu.cn
}

\begin{abstract}
The search ability of multi-objective optimization methods based on decomposition strategy is often reduced due to the unreasonable distribution of weight vectors. To solve this problem, a new method of generating weight vector is designed and a multi-objective optimization method based on decomposition of weight vectors generated by Latin Hypercube algorithm, named Multi-objective Evolutionary Algorithm Based on Decomposition (MOEA/DL), is proposed. Firstly, a random Latin hypercube matrix is generated. Then, the simulated annealing algorithm is used to search the matrix and a Latin hypercube satisfying the specific distribution requirements is obtained. Finally, the Latin hypercube matrix is transformed into a set of weight vectors by normalization for multi-objective optimization algorithm. Through simulation on standard DTLZ1 3 test function, the convergence and distribution of the proposed method are better than those of Multi-objective Evolutionary Algorithm Based on Decomposition (MOEA/D) in Pareto frontier. This method can be directly applied to other multi-objective optimization based on decomposition to generate weight vectors. The evaluation criteria of simulated annealing algorithm can also be changed to obtain the desired weight vectors distribution, which means the proposed method is highly adjustable and flexible.
\end{abstract}

Keywords: Latin hypercube, simulated annealing, decomposition-based multiobjective optimization, weight vector generation. 


\title{
DIMENSIONAL BEHAVIOR OF RECYCLED POLYPROPILENE
}

\author{
Isabel Clavería $^{1(\square)}$, Daniel Elduque ${ }^{1}$, Carlos Javierre $^{1}$, Carmelo $^{\left(\text {Pina }^{2}\right.}$, Raquel Acero $^{3}$ \\ ${ }^{1}$ Department of Mechanical Engineering, University of Zaragoza, María de Luna, 3, 50018 \\ Zaragoza, Spain \\ isabel.claveria@unizar.es \\ delduque@unizar.es \\ carlos.javierre@unizar.es \\ ${ }^{2}$ BSH Electrodomésticos España, S.A., Avda. de la Industria, 49, 50016 Zaragoza, Spain \\ carmelo.pina@bshg.com \\ ${ }^{3}$ Department of Design and Manufacturing Engineering, University of Zaragoza EINA, Maria \\ de Luna 350018 Zaragoza, Spain \\ racero@unizar.es
}

\begin{abstract}
Usage of recycled polypropylene instead of raw polypropylene arises as one of the most promising methods to reduce costs and environmental impact in the field of injection molding manufacturing. As molecular changes are induced in the material during recycling process, manufacturing process conditions should be rearranged in order to keep the quality of the product when original material is substituted by recycled one. This paper analyzes, by means of CAE simulation the dimensional behavior of an industrial component injected by both, raw and recycled material. Results obtained with CADMOULD ${ }^{\circledR}$ show that post-process displacements are reduced when recycled material is used due to the lower no flow temperature of the recycled material. It allows a more efficient holding stage reducing shrinkage and induced warpage after ejection of the component.
\end{abstract}

Keywords: warpage, shrinkage, recycled, polymer. 


\title{
Extendable Hybrid approach to detect conscious states in a CLIS patient using machine learning
}

\author{
V. S. Adama ${ }^{1}$, S.-J. $\mathrm{Wu}^{1(घ)}$, N. Nicolaou ${ }^{2,3}$, and M. Bogdan ${ }^{1}$ \\ ${ }^{1}$ Computer Engineering, Leipzig University, Leipzig, Germany \\ ${ }^{2}$ Medical School, University of Nicosia, Cyprus \\ ${ }^{3}$ Centre for Neuroscience and Interdisciplinary Brain Research (CENIBRE), University of \\ Nicosia Medical School, Nicosia, Cyprus \\ adama | shanglu | bogdan @informatik.uni-leipzig.de \\ nicolaou.niceunic.ac.cy
}

\begin{abstract}
In this study a method for uncovering consciousness in complete locked-in syndrome (CLIS) patients is proposed. The main characteristic of CLIS patients is sufficiently intact cognition, but complete paralysis. It is, thus, vital to develop alternative means of communicating with CLIS patients, and braincomputer interfaces offer a possible platform to do so. A major issue in the study of consciousness in CLIS patients is that there is no certitude regarding their actual state of consciousness. Existing methods provide only a probability of what the states of the patients might be at each moment. This paper proposes a hybrid system based on the combination of complex coherence, sample entropy and Granger causality to uncover the underlying state of consciousness in a CLIS patient from electrocorticography signals. The contribution of each method to the system is determined using machine learning techniques. The aim of the research is to increase the probability of correctly detecting the patients' consciousness states and, ultimately, use that to develop a reliable brain-computer interfacebased communication tool.
\end{abstract}

Keywords: Consciousness, Electrocorticography, Locked-in state, Coherency, Multiscale entropy, Granger causality. 


\title{
Machine learning and the digital era from a Process Systems Engineering perspective
}

\author{
José Luis $\operatorname{Pitarch}^{1[O R C I D](\varpi)}$ and César de $\operatorname{Prada}^{2[O R C I D]}$ \\ ${ }^{1}$ Systems Engineering and Automatic Control department, EII, Universidad de Valladolid, \\ C/Real de Burgos s/n, 47011 Valladolid, Spain \\ jose.pitarcheautom.uva.es \\ ${ }^{2}$ Institute of Sustainable Processes (IPS), Universidad de Valladolid, \\ $\mathrm{C} /$ Real de Burgos s/n, 47011 Valladolid, Spain \\ prada@autom.uva.es
}

\begin{abstract}
Modern sensorization, communication and computational technologies provide collecting and storing huge amounts of raw data from large cyberphysical systems. These data should serve as the basis to take better decisions at all levels (from the design to operation and management). Nevertheless, raw data needs to be transformed in useful information, usually in the form of prediction models. Machine learning plays thus a key role in this task. The process industry is not alien to this digital transformation, although large processing plants present particularities that differentiate them from other systems. These differences, if neglected, can make machine learning for general purpose fail in extracting the right information from data, leading thus to unreliable process models. As such models are the basis on which the ideas towards the cognitive plant rely, this issue is of key importance for a successful full digitalization of the process industry. Here we discuss these aspects, as well as the more suitable machine-learning approaches, through our experience in an industrial case study.
\end{abstract}

Keywords: machine learning, data conditioning, process modeling, data reconciliation, constrained regression, grey-box models. 


\title{
Analyzing the Effects of Geometrical and Particle Size Uncertainty in Circulating Fluidized Beds using CPFD Simulation
}

\author{
Janitha C. Bandara $^{1} \quad$ Britt M.E. Moldestad ${ }^{1} \quad$ Marianne S. Eikeland $^{1}$ \\ ${ }^{1}$ Department of Process, Energy and Environmental Technology, University of South-eastern Norway, Norway \\ \{janitha.bandara, britt.moldestad, Marianne.Eikel and\}@usn.no
}

\begin{abstract}
Computational fluid dynamic modeling and simulation is becoming a useful tool in detailed analysis of multiphase flow systems. The level of uncertainty is different depending on selected modeling concept and numerical schemes. Physical uncertainties originated from geometrical dimensions and particle properties are important aspects. In this work, CPFD method was used to analyze the effect of loopseal pipe diameter and particle size distribution in a circulating fluidized bed. Five different diameters were studied and $32 \%$ growth in particle circulation was observed as the diameter reduced from $30 \mathrm{~mm}$ to $26 \mathrm{~mm}$. The pressure prediction was low compared to experimental data and slight improvement was observed at reduced loopseal diameters. The effect of slight changes in the particle size distribution was negligible and the particle circulation rate reduced by $32 \%$ with monodisperse particles of mean size.
\end{abstract}

Key words: CPFD simulation, uncertainty, circulating fluidized bed, particle circulation rate 


\title{
Control-Oriented Modelling and Simulation - the Impact to the INMOTION Project
}

\author{
Borut Zupančič, Gašper Mušič, Maja Atanasijević-Kunc, Sašo Blažič, Milan Simčič \\ University of Ljubljana, Faculty of Electrical Engineering \\ borut.zupancic@fe.uni-lj.si
}

\begin{abstract}
Engineering higher education programs have computer modelling and simulation engineering (CMSE) content as an import part inside several courses.

InMotion (Innovative teaching and learning strategies in open modelling and simulation environment for student-centered engineering education) (2016-2019) is an ERASMUS+ project in the field of higher education with the general aim to continue there forms in engineering higher education at countries in Russian Federation and in Malaysia and to improve the quality of education.

New and renewed courses are based on textbooks and books of problems developed by project participants. The books will be freely available to students in both English and Russian.

In addition to textbooks, eLearning courses have already been developed,which at the end of the project will be freely available on the Internet.

The EU partners which take care for the transfer of knowledge and experiences are: University Bremen as the main coordinator, University of Ljubljana and National Distance Education University (UNED).
\end{abstract}




\title{
Traffic Jam Assist Simulation and Analysis
}

\author{
J. Echeto ${ }^{1}$, M. Santos ${ }^{2}$ and M. G. Romana ${ }^{3}$ \\ ${ }^{1}$ Department of Computer Engineering, National University of Distance Education, C/ Juan del \\ Rosal s/n, 28015, Madrid, Spain \\ javierecheto@hotmail.com \\ ${ }^{2}$ Department of System Engineering and Automatic Control, University Complutense of \\ Madrid, C/ Profesor García Santesmases, 9, 28040 Madrid, Spain \\ msantos@ucm.es \\ ${ }^{3}$ Department of Transportation, Universidad Politécnica de Madrid, 28040 Madrid, Spain \\ manuel.romana@upm.es
}

\begin{abstract}
.
In the near future travelling in autonomous and connected cars will be a daily experience. Finding approaches for comfortable and safe driving is a must. Driver desired comfort, road conditions, travel dynamics and communication requirements between vehicles have to be considered. Simulation can help us to find how to improve road safety and comfort in traveling. Traffic flow models have been widely used in recent years to improve traffic management through understanding how current laws, with human drivers, should change in this new environment. Early attempts to driving modelling were restricted to the macroscopic level, mimicking continuous physical patterns, particularly waves. However, extensive improvements in technology have allowed the tracking of individual drivers in more detail. In this paper, the Intelligent Driver Model (IDM) is used to examine traffic flow behavior at a vehicle level with emphasis on the relation to the preceding vehicle, similarly as it is done by the Adaptive Cruise Control (ACC) systems nowadays. This traffic model has been modified to simulate vehicles at low speed and the interactions with their preceding vehicles; more specifically, in traffic congestion situations. This traffic jam scenario has been analyzed with a developed simulation tool. The results are encouraging, as they prove that automatic car speed control can potentially improve road safety and reduce driver stress.
\end{abstract}

Keywords: Simulation, Traffic flow, Congested traffic, Traffic Jam, Intelligent Driver Model, Optimization. 


\title{
Optimized Balance of Plant for a medium-size PEM electrolyzer. Design, Modelling and Control
}

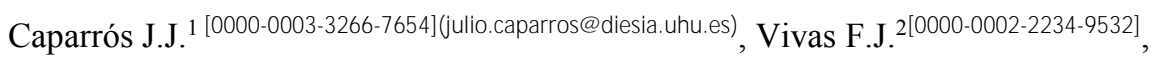 \\ Segura F. ${ }^{3[0000-0002-9969-8773]}$ and Andújar J.M. ${ }^{40000-0002-0631-0021]}$
}

${ }^{1}$ Grupo de Investigación de Control y Robótica TEP-192, Departamento de Ingeniería Electrónica, de Sistemas Informáticos y Automática, Escuela Técnica Superior de Ingeniería. Universidad de Huelva, Spain. julio.caparrosediesia.uhu.es

${ }^{2}$ Grupo de Investigación de Control y Robótica TEP-192, Departamento de Ingeniería Electrónica, de Sistemas Informáticos y Automática, Escuela Técnica Superior de Ingeniería. Universidad de Huelva, Spain.

francisco.vivas@iesia.uhu.es

${ }^{3}$ Grupo de Investigación de Control y Robótica TEP-192, Departamento de Ingeniería Electrónica, de Sistemas Informáticos y Automática, Escuela Técnica Superior de Ingeniería. Universidad de Huelva, Spain.

francisca.seguraldiesia.uhu.es

${ }^{4}$ Grupo de Investigación de Control y Robótica TEP-192, Departamento de Ingeniería Electrónica, de Sistemas Informáticos y Automática, Escuela Técnica Superior de Ingeniería. Universidad de Huelva, Spain. andujar@uhu.es

\begin{abstract}
This paper presents the design, modelling and control simulation of the Balance of Plant (BoP) for a medium-size PEM (Proton Exchange Membrane) electrolyzer. Taking into consideration the main chemical process that occurs in the electrolysis of a PEM electrolyzer, the BoP must be clearly divided into two main parts: water management and hydrogen production. An exhaustive control system is developed to test the working conditions that will allow the PEM electrolyzer to generate hydrogen in a safe and efficient way. The aim of this study is to find an equilibrated solution between minimal BoP and a correct performance, always into safety conditions of hydrogen generation. Automation software is used to model the system and perform a control logic, according to the desirable operation of the PEM electrolyzer. The BoP developed, along with the electrolyzer model and the control logic proposed contribute the PEM electrolysis technology to be expanded in the industrial market and the hydrogen to be widely used as energy carrier, as part of the renewable energy systems.
\end{abstract}

Keywords: PEM electrolyzer, Balance of Plant, Design and Modelling. 


\title{
Machine Learning Perspectives in Concentrating Solar Thermal Technology
}

\author{
Javier Bonilla ${ }^{1,2[0000-0002-2322-2867](\square) ~}$ \\ Jose A. Carballo $2,3[0000-0003-0529-5672]$ \\ Manuel Berenguel 3,2[0000-0002-3349-7506] \\ Jesús Fernández-Reche ${ }^{1 \text { [0000-0003-1967-7823] }}$ \\ Loreto Valenzuela ${ }^{10000-0001-9505-8333]}$ \\ 1 CIEMAT - Plataforma Solar de Almería, Tabernas, Almería, Spain \\ javier.bonillaepsa.es \\ 2 CIESOL - Research Centre for Solar Energy, UAL-PSA.CIEMAT Centre, Almería, Spain \\ 3 University of Almería, Ctra. Sacramento s/n, 04120 Almería, Spain
}

\begin{abstract}
The strategic research agenda of the European technology platform on smart systems integration states that smart system-based devices play a key role for achieving higher energy efficiencies and an intelligent use of energy. Nonetheless, solar thermal plants have not yet incorporated innovations included in other industrial sectors, since solar thermal components incorporate a low degree of intelligence and autonomy in general. Machine learning can contribute to the development of smart solar thermal components. This work reviews some machine learning application in solar thermal energy, draws new potential applications, and presents some machine learning initiatives at Plataforma Solar de Almería.
\end{abstract}

Keywords: Concentrated Solar Power, Solar Thermal Energy, Machine Learning, Artificial Neural Network, Computer Vision. 


\title{
An Adaptable Full-Scale Aircraft Cabin Simulator for Human-in-the-Loop Simulations
}

\author{
Mario Kallenbach ${ }^{[0000-0001-6665-5817](\square)}$, Stephan Kocks ${ }^{[0000-0002-4086-4220](\square)}$, and \\ Thomas Feuerle \\ Institute of Flight Guidance, Technische Universität Braunschweig, Hermann-Blenk-Str. 27, \\ 38108 Braunschweig, Germany \\ m.kallenbach|s.kocks@tu-braunschweig.de
}

\begin{abstract}
An aircraft cabin is - apart from interactions with the cabin crew the most important interface between an airline and its passengers. Not only in this relation but in most high level aviation processes, humans play a key role. Therefore, simulations used for the validation of new systems and processes in the context of aircraft cabins - should consider the human influence and thus be human-in-the-loop simulations. As a technical means to enable human-in-theloop simulations for comprehensive studies, the Institute of Flight Guidance (IFF) of the Technische Universität Braunschweig developed and built a full-scale aircraft cabin section as a simulator. It comprises the structure and electronic systems of a short- to medium-haul single-aisle commercial aircraft. In this paper, we describe the motivation and the approach of the simulations as well as the ongoing work of setting up the cabin simulator. This includes the developed solutions to a variety of technical challenges and our structural hard- and software architecture.
\end{abstract}

Keywords: Human-In-The-Loop-Simulation, Aircraft Cabin Simulator, Aircraft Systems and Procedures. 


\title{
Quick, Stat!: A Statistical Analysis of the Quick, Draw! Dataset
}

\author{
Raul Fernandez-Fernandez ${ }^{\circledR}\left(\square^{\natural}\right)$, Juan G. Victores ${ }^{\circledR}$, David Estevez ${ }^{\circledR}$, and Carlos \\ Balaguer ${ }^{(}$ \\ All of the authors are members of the Robotics Lab research group within the Department \\ of Systems Engineering and Automation, Universidad Carlos III de Madrid (UC3M).

$$
\text { raufernaling.uc } 3 \mathrm{~m} \text {. es }
$$

\begin{abstract}
The Quick, Draw! Dataset is a Google dataset with a collection of 50 million drawings, divided in 345 categories, collected from the users of the game Quick, Draw!1 . In contrast with most of the existing image datasets, in the Quick, Draw! Dataset, drawings are stored as time series of pencil positions instead of a bitmap matrix composed by pixels. This aspect makes this dataset the largest doodle dataset available at the time. The Quick, Draw! Dataset is presented as a great opportunity to researchers for developing and studying machine learning techniques. Due to the size of this dataset and the nature of its source, there is a scarce of information about the quality of the drawings contained. In this paper a statistical analysis of three of the classes contained in the Quick, Draw! Dataset is depicted: mountain, book and whale. The goal is to give to the reader a first impression of the data collected in this dataset. For the analysis of the quality of the drawings a Classification Neural Network was trained to obtain a classification score. Using this classification score and the parameters provided by the dataset, a statistical analysis of the quality and nature of the drawings contained in this dataset is provided.
\end{abstract}

Keywords: Quick, Draw! Dataset, Statistical Analysis, Neural Networks. 


\title{
Role of human resources on TQM benefits
}

\author{
Jorge Luis García Alcaraz ${ }^{10000-0002-7092-6963](\Xi)}$, Juan Carlos Sáenz Diez-Muro ${ }^{2[0000-}$ \\ 0001-7996-3587] and Emilio Jiménez Macías ${ }^{3[0000-0001-6749-4592] ~}$ \\ ${ }^{1}$ Department of Industrial and Manufacturing Engineering, Autonomous University of Ciudad \\ Juarez, Av. Del Charro 450 Norte, 32310 Ciudad Juárez, Mexico \\ jorge.garcia@uacj.mx \\ ${ }^{2,3}$ Department of Electric Engineering, University of La Rioja, San José de Calazans 31, 26004 \\ Logroño, La Rioja, Spain \\ emilio.jimenez@unirioja.es ${ }^{2}$, juan-carlos.saenz-diez@unirioja.es ${ }^{3}$
}

\begin{abstract}
La administración total de la calidad (TQM) es una herramienta de manufactura esbelta que se enfoca en garantizar la producción de bienes que cumplan con especificaciones de diseño y los beneficios que ofrece son ampliamente buscados por los gerentes. Sin embargo, son muchos los factores que intervienen en el éxito de los programas de TQM y muchos de ellos son aspectos culturales asociados a los recursos humanos. En este artículo se presenta un modelo de ecuaciones estructurales que integra tres variables latentes asociados a los recursos humanos internos: el compromiso gerencial, la integración de empleados, la educación y entrenamiento, mismas que se relacionan con los beneficios operacionales obtenidos en un sistema productivo. Las variables se relacionan mediante seis hipótesis, mismas que son evaluadas con información obtenida de 398 respuestas a un cuestionario aplicado a la industria manufacturera. Además, se reporta un análisis de sensibilidad que analiza las probabilidades de aparición de las variables en niveles bajos y altos. Las hipótesis se validan estadísticamente con la técnica de mínimos cuadrados parciales y los resultados demuestran que los factores humanos juegan un papel importante en el éxito de TQM, ya que los efectos directos, indirectos y totales que tiene el compromiso gerencial, la integración de empleados y los procesos de educación y entrenamiento sobre los beneficios obtenidos de la implementación de TQM son estadísticamente significativos a un 95\% de confianza.
\end{abstract}

Keywords: TQM, PLS, SEM, human resources. 


\title{
The simulation modeling as the part of grid methods of uniform probing for the dynamic stochastic systems investigation
}

\begin{abstract}
G. M. Antonova
Institute of Control Sciences Russian Academy of Sciences, Profsoyuznaya str., 65, 117997

Moscow, Russia

gmanteipu.ru

Abstract. The article describes the application of simulation models for the dynamic stochastic systems investigation. At the same time the relationship of the grid methods of uniform probing with grid methods of mathematical physics is considered. The analysis of procedures that extend the capabilities of this approach for the study of poorly formalized systems, which have in their description a set of non-differentiable functions, is carried out. The content of main stages of grid methods of uniform probing using simulation models to describe the systems under research or design is considered. Examples of research and approximate optimization of dynamic stochastic systems presented by simulation statistical models illustrate the proposed approaches. These models are previously created and tested for adequacy, but the problems of preparation of simulation models are not included in the list of topics of the article. Some results for designing of telecommunication systems and microelectronic devices show the effectiveness of grid methods of uniform probing.
\end{abstract}

Keywords: simulation, optimization, grid method. 


\section{Using Deep Learning to classifier emotions in images in the tourism field}

Diaz S. ${ }^{1[0000-0003-0347-8344](\square)}$, Torres, J.M..$^{2[0000-0003-4391-0170]}$, and Aguilar, R.M. ${ }^{3[0000-0002-6531-8584] ~}$

1 Dpto. de IngenierÃa Inform $\tilde{A}_{i}$ tica y de Sistemas. Universidad de La Laguna, Camino San Francisco de Paula, s/n, San Cristobal de La Laguna, Tenerife, Santa Cruz de Tenerife, Spain sdiazgon@ull.edu.es

2 Dpto. de IngenierÃa Inform $\tilde{A}_{i}$ tica y de Sistemas. Universidad de La Laguna, Camino San Francisco de Paula, s/n, San Cristobal de La Laguna, Tenerife, Santa Cruz de Tenerife, Spain

jmtorres@ull.edu.es

3 Dpto. de IngenierÃa Inform $\tilde{A}_{i}$ tica y de Sistemas. Universidad de La Laguna, Camino San Francisco de Paula, s/n, San Cristobal de La Laguna, Tenerife, Santa Cruz de Tenerife, Spain raguilareull.edu.es

Abstract. New digital trends have changed the way we understand the world. And, of course, also diverse interrelations, such as tourism: how the travel is booked, the experience is shared or excursion is programmed. As a result, making a right analysis is basic to succeed when taking the best actions in a sector like this, where images take a fundamental value. Both for reaching the potential customer and for knowing the perception experienced by the tourist better in the destination. So to perceive the projected emotion can be essential for classifying destination strengths and weaknesses, and to create touristic promotions more effective. Even more in a sector where the competition between destinations is very strong. This article provides a framework to classify the tourist's emotions. A framework created by open source software tools. First, this includes the taking of the photographs of the tourist scope and the recognition of the faces. And second and the most important, the classification starting from the generation of a classifier by means of deep learning techniques.

Keywords: Deep learning, Machine learning, Tourism, Sentiment, Emotions. 


\title{
Identification and Validation of a Barge Floating Offshore Wind Turbine Model with Optimized Tuned Mass Damper
}

\author{
D. Villoslada ${ }^{1}$, M. Santos ${ }^{2}$ and M. Tomás-Rodríguez ${ }^{3}$ \\ ${ }^{1}$ University Complutense of Madrid, C/ Profesor G. Santesmases 9, 28040 Madrid, Spain \\ davilIos@ucm.es \\ ${ }^{2}$ University Complutense of Madrid, C/ Profesor G. Santesmases 9, 28040 Madrid, Spain \\ msantos @ucm.es \\ ${ }^{3}$ City, University of London, London, UK \\ Maria.Tomas-Rodriguez,1@city.ac.uk
}

\begin{abstract}
Floating offshore wind turbines (FWOT) stand as a promising concept to expand the wind energy generation into the more productive deep-water areas, where conventional bottom-fixed turbines are infeasible. Barge-type floating wind turbines experience an inverted pendulum effect which produces a coupling with the wind turbine response, resulting in large structural loads. In this paper, we apply passive structural control in the form of a tuned mass damper, installed in the nacelle to mitigate the tower fatigue. A linear dynamics model for the barge-type offshore wind turbine is formulated based on Lagrange's equations. The parameter identification for this model is performed using the FAST-SC simulation software to produce synthetic experimental reference data. A thorough validation study was carried out to select the optimal free-decay initial conditions and test duration to obtain the most suited model parameters. It was found that the 3 degrees initial platform pitch tests began sufficiently far from rest to allow the dynamics to be characterized, but not so far to be affected by the unmodeled non-linearities. Once the model was ready to simulate the system properly, an optimization of the TMD parameters is carried out using genetic algorithms, taking the tower fatigue as a fitness function, derived from the tower top displacement. The results show this tuned conventional passive structural control can help to absorb the vibrations of the structure, reducing the tower fatigue by $50 \%$.
\end{abstract}

Keywords: Identification, simulation, barge-type floating wind turbine, passive structural control, genetic algorithms. 


\title{
Analytical design and validation of OWC chamber device models by means of real-time experimental data
}

\author{
Aitor J. Garrido ${ }^{1,2(\underline{\underline{\Theta}})}$, Erlantz Otaola ${ }^{3}$, Manuel De la Sen ${ }^{1,2}$ and Izaskun \\ Garrido $^{1,2}$ \\ ${ }^{1}$ Automatic Control Group - ACG. Inst. of Research and Development of Processes - IIDP. \\ Dept. Aut. Control and Systems Eng., Faculty of Engineering of Bilbao, University of the \\ Basque Country (UPV/EHU), $\mathrm{P}^{\circ}$ Rafael Moreno 3, Bilbao, 48013. Spain \\ \{aitor.garrido; izaskun.garrido\}@ehu.es \\ ${ }^{2}$ Inst. of Research and Development of Processes - IIDP. Department of Electricity and \\ Electronics, Faculty of Science and Technology, University of the Basque Country \\ (UPV/EHU), Barrio Sarriena s/n, Leioa, 48940. Spain \\ manuel.delasen@ehu.es \\ ${ }^{3}$ Tecnalia Electric Aircraft, Tecnalia Research and Innovation. San Sebastian. 20009. Spain \\ otaola06@gmail.com
}

\begin{abstract}
Ocean Energy Europe has highlighted that wave energy could harness over 3000TWh/year, which is the bulk European energy demand. Moreover, the USA Department of Energy has also stated that their wave resource potential is 1,594-2,640 TWh/year. In general the estimates for wave energy production agree in a significant size that may vary from $4000 \mathrm{TWh} / \mathrm{yr}$ to $29500 \mathrm{TWh} / \mathrm{yr}$. To date, Oscillating Water Column (OWC) converters are the most successful wave energy converters, well above those extracting the energy from buoyancy or diffraction forces; besides, the OWC concept is designed to exploit the wave energy from a broad variety of both fixed and floating structures. This article proposes a holistic approach to the design of on-shore OWC, with a model parameterized and validated for the particular case of Nereida MOWC wave power system using ad-hoc real data from Mutriku's power plant.
\end{abstract}

Keywords: Real-Data Analysis, Data Validation, Modelling, Wave Energy, OWC, Capture Chamber. 


\title{
Guarantying consistency of spatio-temporal regions that solve air traffic conflicts
}

\author{
Thimjo Koca ${ }^{1[0000-0002-8889-8008](\square)}$ and Miquel Angel Piera ${ }^{2}$ \\ 1 Department of Telecommunications \& System Engineering, Autonomous University of \\ Barcelona, Carrer Emprius, 2, 08202 Sabadell, Spain \\ thimjo.kocaluab.cat \\ 2 Department of Telecommunications \& System Engineering, Autonomous University of \\ Barcelona, Carrer Emprius, 2, 08202 Sabadell, Spain \\ miquelangel.piera@uab.cat
}

\begin{abstract}
Separation management together with more efficient conflict detection $\&$ resolution are two of the main challenges that Air Traffic Management faces in its quest to modernize itself. This quest for modernization comes as a result of the necessity to adapt to the increment in demand and complexity of the projected future air traffic. Several approaches are proposed to the problem and several sets of properties that they should satisfy. We identify among them robustness, the ability to provide realistic solutions, and consideration of uncertainties the most critical ones. These properties should of course come at a reasonable computational cost. Among the various approaches towards the problem, we believe the ones that try to solve conflicts using spatio-temporal regions are the most adequate base for such systems, because of their unique ability to consider post-decitional uncertainties. In one of the two such methodologies, the construction of such regions, can produce several inconsistencies. We present in this work a methodology by which such inconsistencies can be taken care of.
\end{abstract}

Keywords: Air Traffic Management, Conflict Resolution, Spatio-Temporal Regions, Computational Geometry. 


\title{
Industrial AGV holistic modelling approach
}

\author{
Jesús Enrique Sierra ${ }^{1,2}(\varpi)$ \\ ${ }^{1}$ Department of Civil Engineering, University of Burgos, 09006 Burgos, Spain \\ ${ }^{2}$ ASTI Mobile Robotics, 09390 Burgos, Spain \\ enriquesglasti.es
}

\begin{abstract}
The acronym AGV comes from the term Automatic Guided Vehicle. They are unmanned transport vehicles used in the industrial sector to substitute manned industrial trucks and conveyors. An AGV is a multivariable complex system composed by several subsystems and strongly coupled variables inside. In order to get realistic simulators of its complete behavior, a holistic modelling approach must be adopted. Therefore, in this work the architecture of an industrial $\mathrm{AGV}$ is exposed, the modelling equations are proposed and the interaction between the subsystems is identified. The architecture of the system is decomposed in the subsystems: Control, Safety, Driving, Guiding and Localization, Power Storage and Charging. The kinematics equations of a tricycle vehicle are obtained. An extended hybrid automata formalism is used to define the behavior of the Safety System and the Control System. Finally, the electrical equivalent circuit of the batteries, charger and the motors is studied.
\end{abstract}

Keywords: Modelling, AGV, hybrid automata, tricycle kinematic, electrical equivalent circuit. 


\title{
Towards Clothes Hanging via Cloth Simulation and Deep Convolutional Networks
}

\author{
David Estevez $(\square)\left({ }^{\circledR}\right.$, Juan G. Victores ${ }^{(}$, \\ Raul Fernandez-Fernandez ${ }^{\circledR}$, and Carlos Balaguer ${ }^{\circledR}$ \\ RoboticsLab, University Carlos III of Madrid, Calle Butarque 15, 28911 Madrid, Spain \\ destevez@ing.uc3m.es
}

\begin{abstract}
People spend several hours a week doing laundry, with hanging clothes being one of the laundry tasks to be performed. Nevertheless, deformable object manipulation still proves to be a challenge for most robotic systems, due to the extremely large number of internal degrees of freedom of a piece of clothing and its chaotic nature. This work presents a step towards automated robot clothes hanging by modelling the dynamics of the hanging task via deep convolutional models. Two models are developed to address two different problems: determining if the garment will hang or not (classification), and estimating the future garment location in space (regression). Both models have been trained with a synthetic dataset formed by 15000 examples generated though a dynamic simulation of a deformable object. Experiments show that the deep convolutional models presented perform better than a human expert, and that future predictions are largely influenced by time, with uncertainty influencing directly the accuracy of the predictions.
\end{abstract}

Keywords: robotics, deformable objects, laundry, deep learning. 


\title{
Floating Offshore Wind Turbines Oscillations Damping
}

\author{
M. Tomas-Rodriguez ${ }^{1}$, K. Feroz ${ }^{1}$, and M. Santos ${ }^{2}$ \\ 1 City, University of London. United Kingdom \\ Maria.Tomas-Rodriguez.1@city.ac.uk \\ ${ }^{2}$ Universidad Complutense de Madrid, Spain \\ msantos@ucm.es
}

\begin{abstract}
This article deals with the modelling and control of oscillations that appear on floating offshore wind turbines (FOWT). First, these offshore wind energy systems, located in deep waters, are described and the modeling approach is presented. Secondly, the traditional structural control strategies based on tuned mass-damper (TMD) systems for oscillations reduction are complemented with a passive mechanism called inerter in order to improve the performance of the structural controller. This work is based on a previous work by the authors in which the inerter was located in parallel to an existing TMD in the nacelle of the FOWT. In this work, the inerter is located between the tower and the barge and results are compared to those obtained previously showing better performance. The results here presented are promising in terms of oscillations damping, both in amplitude and frequency, and constitute preliminary results of the ongoing current research of the authors.
\end{abstract}

Keywords: Modelling, Control, Wind turbine, Floating Offshore wind turbines, marine energy, renewable energy. 


\title{
Methodology to achieve convergence in a rigorous dynamic model of a superfractionator
}

\author{
Erika Oliveira-Silva ${ }^{1,2(\boxminus)}$, Cesar de Prada ${ }^{1,2[0 R C I D]}$ \\ ${ }^{1}$ Department of Systems Engineering and Automatic Control, School of Industrial Engineering, \\ University of Valladolid, Dr. Mergelina s/n, 47011, Valladolid, Spain \\ erika.oliveira@autom.uva.es \\ ${ }^{2}$ Institute of Sustainable Process, Dr. Mergelina s/n, 47011, Valladolid, Spain
}

\begin{abstract}
The modelling of chemical engineering processes usually forms a differentialalgebraic equations (DAE) system. The integration methods used to solve DAE approximate the derivatives by a backward differentiation formula (BDF) and solve the resulting non-linear algebraic equations by Newton Raphson. The method uses different orders for BDF approximations and variable step size in order to limit the integration error. One of the main problems of DAE integration is inconsistent initial values for the state and algebraic variables. A bad initial value decreases the time step to maintain the error bounded and a time step value next to zero jeopardizes the calculation of derivatives updates and the Newton matrix.
\end{abstract}

A rigorous dynamic model for a distillation column usually have more than hundred equations and required dozens of initial values of state and algebraic variables that are difficult to predict at the first moment. Because of that, this paper presents a methodology to find consistent initial conditions for a propylene-propane splitter dynamic model. First, the model structure for the splitter is built with all the mass and heat balance equations for each tray, boiler and condenser in addition to the equilibrium equations that described the molar fraction relation between the liquid and vapor phase. After that, the methodology proposed constructs simplified models based on the full rigorous model, applying assumptions that may not be suitable for the process studied, but decrease the number of initial values required. In each step, the simplified models approximates to the complete rigorous model and a subset of the initial values is found.

Keywords: DAE systems, Initial values, Dynamic Model, Superfractionator 


\title{
Encoder-Decoder LSTM for predicting household electricity consumption using public data
}

\author{
Aguilar, R.M. ${ }^{\text {[0000-0002-6531-8584] }}$, Hamilton, A. ${ }^{\text {[0000-0002-2347-5792](घ) }}$, and \\ Cabrera, P. ${ }^{3[0000-0001-9707-6375]}$ \\ 1 Department of Computer and Systems Engineering, University of La Laguna, \\ 38200 La Laguna (Tenerife), Spain. \\ raguilar@ull.edu.es \\ 2 Department of Computer and Systems Engineering, University of La Laguna, \\ 38200 La Laguna (Tenerife), Spain. \\ albhameull.edu.es \\ 3 Department of Mechanical Engineering, University of Las Palmas de Gran Canaria, \\ Campus Universitario de Tafira sn, 35017, Las Palmas, Spain \\ pedro.cabrerasantana@ulpgc.es
}

\begin{abstract}
Forecasting the electricity consumptions has always been of great interest to the different agents involve in the electricity system. In recent decades, with the introduction of renewable technologies, both in centralized plants, and in a distributed way, this prediction has become an essential task. Many methods have been proposed for predicting long, medium and short term electricity demands. Forecasting at state and regional level has shown a high degree of success. These wide-scope approaches allow to use well-studied time series with well-known characteristics and structures. However, when the problem is tackled using more reduced scopes, as at building or housing level, traditional methods fail due to the complexity and noises of these time series. Numerous studies have pointed that Machine Learning techniques and specially recurrent neural networks (RNN) outperforms traditional techniques at this level.

This study dealt with the problem of short-term electricity consumption forecasting. A method to predict the hourly electricity consumed by individual and residential households -24 hours ahead-is presented. The method is based on the use of a particular version of a long-short term memory (LSTM) recurrent neural network, called Encoder-Decoder LSTM. This is one of the most promising techniques to deal with this kind of problems. The analyses have been carried out with actual data of seven public features corresponding to a period of one year and two months -10223 samples in total. These measures have been collected around the household from different free and open sources available for everybody. The target variable is comprised by past hourly samples of electricity demand values recorded in the house. The house, which is placed in Tenerife -an island from the Canary Islands Archipelago (Spain)- is an individual and familiar household where live four people. The key aim of this research is to investigate whether it is possible to make acceptable predictions for a household electricity consumption using easily and public available data and the Encoder-Decoder LSTM technique.
\end{abstract}

Keywords: LSTM, machine learning, time-series, forecasting, electricity demand, household. 


\title{
Application of CAE to model and simulate wheel-ground contact in railway vehicle
}

\author{
Julian Malaka ${ }^{1[0000-0002-0681-2734](\varpi)}$ \\ ${ }^{1}$ Faculty of Mechanical Engineering, Silesian University of Technology, Konarskiego 18A, \\ 44-100 Gliwice, Poland \\ julian.malaka@polsl.pl
}

\begin{abstract}
Drive is one of the most vital elements of technological machines, transport equipment and vehicles. Its selection process is to ensure appropriate motion parameters, that it why mechanical analysis is crucial. Modern CAE tools facilitate and accelerate designers' work, but they can also be misleading if obtained results are misinterpreted. Scepticism with regard to computer simulations is indispensable so as not to hastily recognise something as an ultimate solution to a given problem hastily. In the software based on the visualisations of designed systems, a user is usually not able to influence the motion-describing equations and the method of solving them directly. Most results can yet be evaluated on the basis of the mathematical descriptions of systems under consideration. This is the procedure which I used to conduct the verification and validation of a model created with the application of a CAE tool. In the article I described the object of the research, the process of its preparation and analysis as well as the results which eventually determine the usefulness of the selected technique in the modelling of vehicle drive mechanics. I named the problems related to the creating of simulations and I suggested solutions to them. The activities carried out provide information helpful in the correct use of the tools that facilitate calculations as well as in the interpretation of the results.
\end{abstract}

Keywords: Modelling, Simulation, Drive, Vehicle, Friction. 


\title{
Review of neural modelling on cardiovascular rehabilitation active processes by using cycloergometers
}

\author{
Gorka Miñano $^{1[\mathrm{ORCID}](\square)}$, Mikel Larrea ${ }^{2[\mathrm{ORCID}]}$, and Eloy Irigoyen ${ }^{2[\mathrm{ORCID}]}$ \\ Department of System Engineering and Automation, University of the Basque Country \\ (UPV/EHU), Alda, Urquijo s/n, E-48013 Bilbao, Vizcaya, Spain
}

\begin{abstract}
This work gathers important developments carried out in a specific area of the Biomedical Engineering which applies advanced models based on Artificial Neural Networks to improve Cardiovascular Rehabilitation (CR) processes by using Cycloergometers. This work presents an updated revision of proposals, focusing on different problems involved in CR and considering features and requirements nowadays taken into account during their modelling processes. Furthermore, the signals analysed in these models are studied and presented below. Among them, a review of solutions applied to CR processes, focused on Computational Intelligence are cited.
\end{abstract}

Keywords: Cardiovascular Rehabilitation, Computational Intelligence, Modelling 


\title{
Advanced machine learning in recursive data-based modelling
}

\author{
Esko K. Juuso \\ Control Engineering, Environmental and Chemical Engineering \\ Faculty of Technology, University of Oulu, Finland \\ esko.juusodoulu.fi
}

\begin{abstract}
Recursive data-based modelling is needed in varying operating conditions to estimate models to make decision on-line, e.g. in adaptive control, adaptive filtering, or adaptive prediction. Recursive identification, adaptive parameter estimation, sequential estimation, and on-line algorithms are used for these algorithms to update the parameters within selected memory horizons. Also abrupt changes can be handled if the situation change is approved to be drastic. Incremental training can be applied to both static and dynamic ANNs: adaptive linear networks are typical examples of this. The identification block typically contains some kind of recursive estimation algorithm which aims at determining the best model of the process at the current instant.
\end{abstract}

The arithmetic means and medians are suitable for recursive tuning, but the resulting scaling functions are narrow and sensitive to outliers. The nonlinear scaling approach use generalized norms to include additional feasible alternatives: the chosen orders adapt to the gradually changing operating conditions gradually improve the understanding about the meanings of the variable. However, this will not be enough if the changing situation really requires new shapes for the scaling functions. These new situations need changes in the orders of the norms. The shape of the scaling function may change drastically. The full analyses of the orders need to be repeated in this case. The orders can also be stored for different situations and re-used if a similar situation is activated later. The database is not extensive since only five parameters, or orders of norm, are needed for a variable in a specific situation.

The feasible ranges of the variables are based on a set of generalized norms. Fuzzy inequalities are used to detect if the feasible ranges of the recent period are different to the current active range or similar with some of the previous feasible ranges. Machine learning is integrated in the system in three levels: (1) finding the appropriate time windows, (2) interactions of the feasible levels, and (3) finding decision support when some of the feasible ranges need to change. These decisions are supported and assessed by expert knowledge. Also other model parameters can be included in the analysis. The solution is tested with measurement data from a solar collector field and condition monitoring from several process units and machines. The recursive approach is beneficial in the control and maintenance in varying operating conditions.

Keywords: intelligent systems, statistical analysis, recursive analysis, fuzzy systems. 


\title{
Simulation of Regular Waves on Floating Wind Turbines: Preliminary Analysis
}

\author{
Segundo Esteban ${ }^{1}$, Rafael Lopez ${ }^{1}$, María Guijarro ${ }^{2}$, and Matilde Santos ${ }^{2}$ \\ ${ }^{1}$ Department of Computer Architecture and Automatic Control, Faculty of Physics, Universidad \\ Complutense de Madrid, 28040 Madrid, Spain \\ sesteban@ucm.es, rlopez@ucm.es \\ ${ }^{2}$ Computer Science Faculty, Universidad Complutense de Madrid, 28040 Madrid, Spain \\ mguijarro@ucm.es, msantos@ucm.es
}

\begin{abstract}
Waves are the main source of disturbances for floating offshore wind turbines (FOWT). These loads have a great influence on the structure and thus, on the fatigue of the system. It is important to study their behaviour since the coupling of the frequency of the waves can produce oscillations of great amplitude in the wind turbines, damaging their structure. In this work, the influence of regular waves on the motion of an offshore turbine located on high sea is analysed. To do this, we work with a model of the FOWT that shows the strong coupling between translational, rotational and gyroscopic effects that the wind turbine experiences due to the waves. Regular waves with different frequency and amplitude have been considered. The simulation results allow us to analyse the effect of introducing some possible changes in the configuration of the turbine that could reduce the effect of this load.
\end{abstract}

Keywords: Simulation, Floating Wind Turbine, Waves, Gyroscopic stabilization. 


\title{
A survey of damage control methods for wind turbines based on sensors: a first approach
}

\author{
M. Guijarro, S. Esteban ${ }^{1}$ and M. Santos ${ }^{2}$ \\ ${ }^{1}$ Department of Computer Architecture and Automatic Control, Physics Faculty, Plaza de \\ Ciencias, 28040-Madrid, Spain \\ ${ }^{2}$ Computer Science School, University Complutense of Madrid, C/ Profesor G. Santesmases 9, \\ 28040 Madrid, Spain \\ mguijarro@ucm.es, segundoddacya.ucm.es, msantos@ucm.es
}

\begin{abstract}
Renewable power generation is leaded by wind energy, growing at an impressive rate in the entire world. The maintenance of wind turbines acquires an important relevance, to be able to reduce costs and to increase effectiveness in the solutions of wind energy. When a component of a wind turbine fails with no warning, the turbine may not be able to generate electricity or the damage could be irreparable or with a very high cost for replacement. So, an early detection and an accurate location of the damages of wind turbines though testing, inspecting and monitoring guarantee the service safety of them. This becomes particularly important for floating marine wind turbines, that are far from the coast, in remote places. This paper presents a preliminary review of damage control methods based on non-destructive technics, that can help to reduce operational and maintenance costs, in terms of labors and materials.
\end{abstract}

Keywords: wind turbine, floating offshore wind turbine, damage, structure fatigue, images, sensors. 


\title{
Sequence-to-Sequence Natural Language to Humanoid Robot Sign Language
}

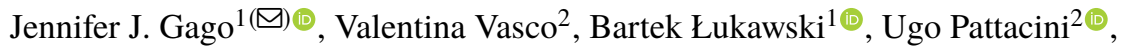

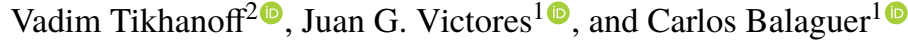 \\ 1 Robotics Lab, Department of Systems Engineering and Automation, University \\ Carlos III of Madrid, Av. Universidad 30, 28911, Leganés, Madrid, Spain \\ jgagoding.uc 3 m.es \\ 2 iCub Facility, Istituto Italiano di Tecnologia, Via Morego 30, 16163, Genova, Italy
}

\begin{abstract}
This paper presents a study on natural language to sign language translation with human-robot interaction application purposes. By means of the presented methodology, the humanoid robot TEO is expected to represent Spanish sign language automatically by converting text into movements, thanks to the performance of neural networks. Natural language to sign language translation presents several challenges to developers, such as the discordance between the length of input and output data and the use of non-manual markers. Therefore, neural networks and, consequently, sequence-to-sequence models, are selected as a data-driven system to avoid traditional expert system approaches or temporal dependencies limitations that lead to limited or too complex translation systems. To achieve these objectives, it is necessary to find a way to perform human skeleton acquisition in order to collect the signing input data. OpenPose and skeletonRetriever are proposed for this purpose and a 3D sensor specification study is developed to select the best acquisition hardware.
\end{abstract}

Keywords: Humanoid Robot, Translator, Sequence-to-Sequence, Sign Language. 


\title{
pyEff: New tool for code efficiency measurement
}

\author{
Guillermo Calvo Álvarez $\left.{ }^{1(}\right)$, Jesús Enrique Sierra ${ }^{2(\boxplus)}$ \\ 1,2 Department of Civil Engineering, University of Burgos, 09006 Burgos, Spain \\ 1 gca0011@alu.ubu.es, ${ }^{2}$ jesierra@ubu.es
}

\begin{abstract}
Nowadays most of modelling and simulation techniques are based on a computational approach. These models must be implemented in some programing language to be interpreted by the machine in charge of the execution of the model. The measurement of the code efficiency is a key point to optimize the resources of the execution. In this work we present an approach to evaluate the efficiency of code. The code is transformed to an operation matrix what accounts the number of operations of each type. Then this matrix is weighted by a translation matrix which collects the set of instructions of a processor. The approach is tested by developing a new tool capable of measuring efficiency of Python code. The tool can make comparisons between different files in order to identify which code has the highest efficiency. The tool is tested with some examples to check the validity of the technique.
\end{abstract}

Keywords: Modelling, code efficiency, computational time. 


\title{
Simulation processes for on-board state estimation in a small UAV environment
}

\author{
Marsel Omeri ${ }^{1[0000-0002-4547-3202]}$,Marko Radanovic ${ }^{2 \text { [0000-0002-8166-0742] }}$, Ernesto \\ Emmanuel Santana Cruz ${ }^{3[0000-0001-9099-7243]}$, Romualdo Moreno Ortiz ${ }^{4[0000-0002-7272-3529]}$ \\ 1,2,3,4 Department of Telecommunications and Systems Engineering \\ Autonomous University of Barcelona \\ Carrer dels Emprius, 2, 08202 Sabadell, Spain \\ marsel.omeri @uab.cat \\ marko.radanovic@uab.cat \\ ernestoemmanuel.santana@uab.cat \\ romualdo.moreno@uab.cat
}

\begin{abstract}
This paper describes the processes for estimating and analyzing the position states on-board small unmanned aerial vehicles in the low-altitude simulation environment. Those processes are explained using two simulation platforms, Robot Operating System and Gazebo. They comprise different system functionalities from the trajectory generation, linear-kinematic trajectory conversion, path controllers, to the modeling and configuration of different aerial vehicles, on-board positioning and navigation sensors and creation and visualization of the simulation environment. We model and simulate the vehicle trajectories, in order to determine 3-D positions from GPS sensor, along with estimated positions from fusion of GPS/IMU and Altimeter. The simulated results have provided a dataset on lateral and vertical trajectory profile guidance and prediction in the low altitude airspaces for follow-up research on the common reference altitude determination, as well as definition of the well clear and collision states for the detect and avoid functions of the small unmanned aerial vehicles.
\end{abstract}

Keywords: small unmanned aerial vehicles, Robot Operating System, state estimation, Gazebo, trajectory simulation 


\section{Adapted Laboratory for Mobile Robotics Teaching and its Application to Coordinated Control of Robots}

David Gallarta Sáenz, Pablo Álvarez Benito, Javier Rico-Azagra and Montserrat GilMartínez

Control Engineering Research Group, Department of Electrical Engineering, University of La Rioja, San José de Calasanz, 31, 26004 Logroño, Spain

\{david.gallarta, pablo.alvarez\}@alum.unirioja.es

\{javier.rico, montse.gil\}@unirioja.es

Abstract. This paper presents a teaching laboratory specially suitable for practical work with mobile robotic systems. The laboratory is composed of a set of low-cost robots and a vision-based data capture system used to localise such robots with precision. All the generated information is centralised on a computer that acts as a link between the different elements. MATLAB-Simulink, a wellknown programming environment, is used for information processing, and it also achieves maximum compatibility with the dynamic control tasks of the robots. To demonstrate the usefulness of the developed software and hardware infrastructure that comprise the laboratory, a coordinated control system involving several robots and using Lloyd's algorithm is presented.

Keywords: Teaching Laboratory, Mobile Robots, Coordinated Control. 


\title{
Genetic Algorithms in the domain of personalized nutrition
}

\author{
Petri Heinonen ${ }^{1}$ and Esko K. Juuso ${ }^{2}$ \\ ${ }^{1}$ Nutri-Flow Oy, Oulu, Finland \\ petri.heinonen@nutri-flow.fi \\ ${ }^{2}$ Control Engineering, Faculty of Technology University of Oulu, Oulu, Finland \\ esko.juusodoulu.fi
}

\begin{abstract}
Lifestyle related public health problems are common around the world. A personal nutrient guidance is a tool to promote healthier lifestyles. Most of the applications available on the market are based on energy only, and a reliable individual assessment and guidance is given by licensed nutritionists. Nutri-Flow has a novel approach into personalized nutrition guidance with Fuzzy Expert System (FES) enhanced with Genetic Algorithms (GA) optimization. While FES assesses the foods and beverages added into a search space, GA is used to find the level of intake for them. The optimization problem is to minimize the distance to ideal nutrient intake levels, and to keep the level of change in a feasible level, and take into account other nutrition variables. In this study, the suitability of GA was assessed. Also, the performance the GA was evaluated and evolved. The objective function is presented and the overall results were evaluated numerically if the system was feasible in the domain of nutrition. The nutritional aspect is not in the scope of this study.
\end{abstract}

Keywords: Genetic Algorithms, Optimization, Nutritional Guidance 


\title{
Python-Based eSES/MB Framework: Model Specification and Automatic Model Generation for Multiple Simulators
}

\author{
Hendrik Folkerts $\left.{ }^{\square}\right)$, Christina Deatcu, and Thorsten Pawletta \\ Faculty of Engineering, Hochschule Wismar, Philipp-Müller-Straße 14, 23966 Wismar, \\ Germany \\ hendrik.folkerts@cea-wismar.de
}

\begin{abstract}
This paper proposes a Python-based infrastructure for studying the characteristics and behavior of families of systems. The infrastructure allows automatic execution of simulation experiments with varying system structures as well as with varying parameter sets in different simulators. Possible system structures and parameterizations are defined using a System Entity Structure (SES). The SES is a high level approach for variability modeling, particularly in simulation engineering. An SES describes a set of system configurations, i.e. different system structures and parameter settings of system components. In combination with a Model Base (MB), executable models can be generated from an SES. Based on an extended SES/MB approach, an enhanced software framework is introduced that supports variability modeling and automatic model generation for different simulation environments. By means of an engineering application it is shown, how a set of Python-based open source software tools can be used to model an SES and to automatically generate and execute signal-flow oriented models.
\end{abstract}

Keywords: System Entity Structure, modelbuilder, model. 


\title{
Military Operational Decision Maker based on Blocks feedback, using uncertainty techniques
}

\author{
G. Minguela Castro a, Carlos Cerradaa , J.A. Cerrada a \\ a Departamento de Ingeniería de Software y Sistemas Informáticos. UNED, \\ C/Juan del Rosal, 16, 28040 Madrid, Spain; gminguela@isdefe.es; \\ ccerrada@issi.uned.es; jcerrada@issi.uned.es;
}

\begin{abstract}
Modelling and simulation are a very important supporting tool for helping in decision-making, especially in the military world. They provide an interpretation of complex environments performance and an assessment of possible scenarios. In many occasions, simulation systems are complemented with Artificial Intelligence (AI) techniques, leading to the improvement in the adversary's behaviour definition. IA performances together with Feedback models can and must be used on military decision making, integrated with adversary models and lies in doctrine. The paper establishes the research fundamentals of the first author's future Thesis work.
\end{abstract}

Keywords:

Combat Models, System Dynamics, Lanchester Equations, War Games 


\title{
Neural Model Applied to a Conversational Agent in a Closed Domain
}

\author{
M. Rodrilguez a,b,_, F. Matia a,b, P. San Segundo a,c
}

a Grupo de Control Inteligente, Centro de Automatica y Robotica (CAR), CSIC-UPM, C/ Jose Gutierrez Abascal, 2, 28006, Madrid, España.

b Dpto. de Automatica, Ingenieria Electrica y Electrónica e Informatica Industrial, Universidad Politécnica de Madrid, C/ Jose Gutierrez Abascal, no2, 28006,

Madrid, España.

c Dpto. de Ingenieria Electrica, Electronica Automatica y Fisica Aplicada, Universidad Politecnica de Madrid, Ronda de Valencia, no3, 28012, Madrid, España.

\begin{abstract}
The present paper surveys the development of a conversational agent designed with the Dual Encoder LSTM model for dialog response generation. The model has been created using Natural Language Processing techniques and Deep Learning technologies. Furthermore, this paper provides a comprehensive study of the impact of critical design parameters, both regarding the network and the model, by analyzing the results obtained from exhaustive simulations varying given parameters. Currently, we are working on the development of a generative conversational agent, implemented with the Sequence to Sequence model and the Attention and Anti-Language mechanisms.
\end{abstract}




\section{Hybrid Models and Digital Twins for Condition Monitoring: HVAC System for Railway}

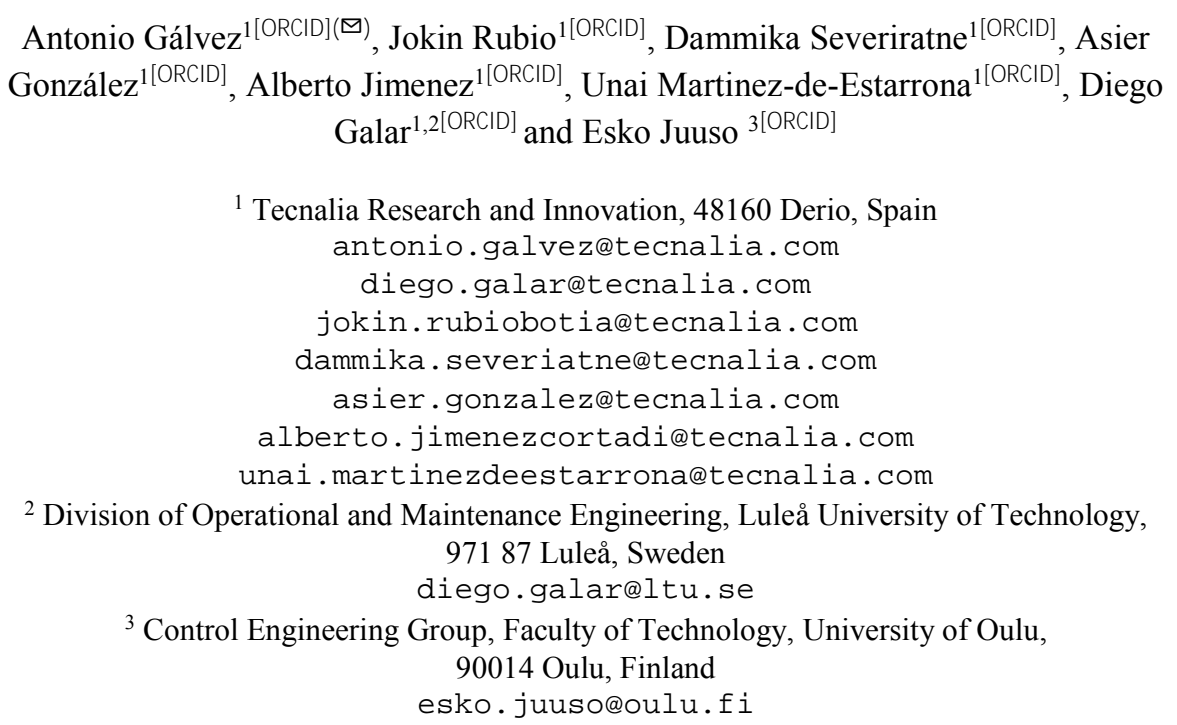

Abstract. The passenger transportation, safety is more important than efficiency or reliability. Therefore, it is vital to maintain the proper condition of the equipment related to the passengers' comfort and safety. This manuscript explains the methodology of complete development and implementation of both hybrid model and digital twin 3.0 for a HVAC in railways. The objective of this is to monitor the condition of the HVAC where it matters to the comfort and safety of the passengers in the trains. The level 3.0 of digital twin will be develop for the diagnosis and prognosis of HVAC by using the hybrid modeling.

The description illustrated in this paper is focused on the methodology used to implement the hybrid model approach and both the need and advantages to use a hybrid model approach instead of the data-based approach.

One of the particularities considered doing the development was the importance of the safety and environmental risk which were included in the risk quantification of the failure modes. In train companies the maintainers replace critical components in early stages of degradation, thus, using a data-based model might loses important information and does not give good support to manage the maintenance instructions. Developing a physics based-model will be able to generate synthetic data for the behavior of the components in advanced stages of degradation and combining it with the data-based model lead to form hybrid model with a large number of failure modes that were unpredictable. Finally, the outcome is beneficial for the proper functioning of the systems, hence, the safety of the passengers.

Keywords: Maintenance, Hybrid model, Digital Twins, HVAC, Railway engineering. 


\title{
Hydraulic Press Commissioning Cost Reductions via Machine Learning Solutions
}

\author{
Ignacio Trojaola $^{1(\square)}$, Iker Elorza $^{1}$, Eloy Irigoyen $^{2}$, and Aron Pujana ${ }^{1}$ \\ 1 Ikerlan Technology Research Centre, Control and Monitoring Area, \\ Arrasate-Mondragon, Spain. \\ itrojaola@ikerlan.es \\ 2 UPV/EHU, Alda. Urquijo S/N, Bizkaia, Spain.
}

\begin{abstract}
In industrial processes, PI controllers remain as the dominant control technique due to their applicability and performance reliability. However, there could be applications where the PI controller is not enough to fulfill certain specifications, such as in the force control loop of hydraulic presses, in which specific pressure profiles need to be ensured in order not to damage the workpiece. An Iterative Learning Control scheme is presented as a Machine Learning control alternative to the PI controller, in order to track the pressure profiles required for any operational case. Iterative Learning Control is based on the notion that a system that realizes the same process repeatedly, e.g. hydraulic presses, can improve its performance by learning from previous iterations. The improvements are revealed in high-fidelity simulations of a hydraulic press model, in which the tracking performance of the PI controller is considerably improved in terms of overshoot and the settling time of pressure signal.
\end{abstract}

Keywords: Hydraulic Presses, Machine Learning, Iterative Learning Control, Force Control 


\title{
Preliminary design of modular electrolyzer for photovoltaic energy utilization in Smart Micro-Grids
}

Julián Seco Martín a, Antonio José Calderón Godoy a, *, Isaías González Pérez a, Manuel Calderón Godoy a

a Departamento de Ingeniería Eléctrica, Electrónica y Automática, Escuela de Ingenierías Industriales, Universidad de Extremadura.

Avenida de Elvas s/n, 06006 Badajoz, España.

\begin{abstract}
Hydrogen generation plays a vital role in the utilization of renewable energies and in the implementation of intelligent grids of power generation and distribution, the so-called Smart Grids. This paper presents the preliminary design of a modular hydrogen generator or electrolyzer that will be fed by a photovoltaic generator in the context of a research project about the development of digital replicas of Smart Micro-Grids. The main elements that compose the electrolyzer as well as the management algorithm are expounded. The control of the equipment will be carried out by a programmable logic controller aiming to avoid the closed commercial systems and, hence, being able to test different intelligent control algorithms.
\end{abstract}

Keywords:

Hydrogen, Smart Micro-Grid, Renewable Energy Systems 


\title{
Human behavior modeling in crowded scenarios by reference nets
}

\author{
Juan-Ignacio Latorre-Biel ${ }^{1[0000-0003-4642-7977](\varpi)}$, Eduardo Martínez Cámara ${ }^{\text {[0000-0002- }}$ \\ 3042-4803], Julio Blanco Fernández ${ }^{\text {[0000-0002-7351-5342] }}$, Mercedes Pérez de la Parte ${ }^{\text {[0000- }}$ \\ 0001-9158-4053], Juan Carlos Sáenz-Díez ${ }^{\text {[0000-0001-7996-3587] }}{ }^{\text {Emilio Jiménez Macías }}{ }^{3 \text { [0000- }}$ \\ 0001-6749-4592] \\ ${ }^{1}$ Institute of Smart Cities. Public University of Navarre. Campus Arrosadía. 31006 Pamplona, \\ Spain. \\ juanignacio.latorre@unavarra.es \\ ${ }^{2}$ Department of Mechanical Engineering, University of La Rioja, Av. de la Paz, 93, 26006 \\ Logroño, Spain \\ eduardo.martinez@unirioja.es \\ julio.blanco@unirioja.es \\ mercedes.perez@unirioja.es \\ ${ }^{3}$ Department of Electrical Engineering, University of La Rioja, Av. de la Paz, 93, 26006 \\ Logroño, Spain \\ juan-carlos.saenz-diez@unirioja.es \\ emilio.jimenez@unirioja.es
}

\begin{abstract}
Human modeling and simulation is a topic that has received attention from the point of view of agent-based methodologies. However, this approach does not provide with detailed information on the complete state of the system. This fact limits the applicability and knowledge on the system itself. A Petri net approach is provided, where the formalism of the reference nets is proposed as suitable tool for modeling and simulation of human behavior in crowded scenarios. A system net provides with the context, where the humans interact and act, while token nets model individuals that interact between them and with the system net. Randomness is introduced in the system in the generation of the token nets, where the objectives and behavior of the individuals is represented. Humans are described as having clear objectives to fulfill in the scenario, where they are simulated. However, discrepancies between a expected situation and real findings, might change the mind of the modeled individuals. As a consequence of this approach, it can be said that the proposed approach presents a significant potential in diverse application fields, such as supermarkets and shopping malls, airports and train stations, road networks, or sport events.
\end{abstract}

Keywords: Petri nets, reference nets, social behavior simulation. 
EUROSIM 2019 Abstract Volume, 10th EUROSIM Congress, La Rioja, Logroño, Spain, July 1-5, 2019 ARGESIM Report 58 (ISBN 978-3-901608-92-6), DOI 10.11128/arep.58

Blockchain techniques applied to Petri Net state space. An approach to ensure security in Petri Net state evolution

\author{
Íñigo Leon ${ }^{1}$, Juan Ignacio Latorre ${ }^{1}$, Emilio Jiménez ${ }^{1}$
}

${ }^{1}$ High Tecnical School of Industrial Engineering, University of La Rioja, c/ San José de Calasanz 31, 26004 Logroño, Spain.

\begin{abstract}
Blockchain is, nowadays, a modern technology used to ensure security and privacy in a very huge amount of different kind of transactions. There are many works that try to join Petri Net and Blockchain worlds. However, these works are always in the way of explaining blockchain analysis or procedures from the Petri Nets point of view, trying to model the blockchain processes through Petri Nets.

In this paper it is going to be explained that Petri Net states are candidates themselves to be "blockchained". In other words, blockchain can be applied to a Petri Net state space in order to ensure the evolution of that Petri Net along the time. And this process can be monitorized, audited and validated by many actors, without having a central manager that organize the process.

Other important aspect of this approach is that, as Petri Nets are a modelling system, any process modelled with Petri Nets can take advantage of the use of blockchain.
\end{abstract}




\title{
Wine Aging in Reused Oak Barrels Sanitized with Carbon Dioxide
}

\author{
Francisco J. Flor ${ }^{1}$, Mercedes Pérez ${ }^{2}$, Emilio Jiménez², Eduardo Martínez², \\ Julio Blanco ${ }^{2}$ \\ ${ }^{1}$ Uniriver Ebro S.L., Lapuebla de Labarca, Alava 01306, Spain \\ ${ }^{2}$ High Tecnical School of Industrial Engineering, University of La Rioja, c/ San José de \\ Calasanz 31, 26004 Logroño, Spain. \\ Corresponding author: M. Pérez; mercedes.perez@unirioja.es
}

\begin{abstract}
The reuse of oak barrels is essential to reduce the high cost of aging. In this study, first, three preliminary tests were performed on Quercus alba barrels with three degrees of toast and with one or two years of vinification. Then, the wines were aged and evaluated analytically and organoleptically. A tasting panel was set up, comprising prestigious enologists from Rioja QDO wineries. Several principal component analyses were performed on barrels and wines. With aging, the wine evolved generally towards lower values for color intensity, and a predominance of vanillin and 5-methylfurfural. Its olfactory description evolved towards "vanilla" and its gustatory description, towards "spices" and "vanilla". After cleaning and aging, the chemistry and properties of wine remained differentiated and changed more by increasing the degree of barrel toast. Cleaning barrels by spraying them with carbon dioxide will reduce the production costs without loss of quality.
\end{abstract}

Keywords: Sanitation, Aging, Volatile Compound, Organoleptic Description, Quality 


\section{Carbon dioxide as a new oak barrel cleaning process. Influences on the volatile compounds of oak-wood.}

\footnotetext{
Autors

Francisco J. Flor, Mercedes Pérez, $*, \dagger, \ddagger$ Emilio Jiménez,,,$\ddagger$ Eduardo Martínez $, \dagger, \ddagger$ and Julio Blanco

Department of Mechanical Engineering and Department of Electrical Engineering, University of

La Rioja, Logroño, Spain

E-mail: mercedes.perez@unirioja.es

Phone: +34 941299535. Fax: +34 941299794

La Rioja (Spain) has one of the largest parks of wine-making oak barrels in the world. The penetration of microorganisms into the barrels over the years increases the risks of wine spoilage. Therefore it is necessary to develop effective and economically viable cleanliness technologies so that the barrels may be reused. This paper presents a new treatment based on carbon dioxide spraying. An exploratory test of the ability to remove tartrate crystal and a quantitative statistical test of Brettanomyces yeast reduction have been carried out. The results have been compared with most widely- implemented sanitation technologies in the sector. Additionally some volatile wood compounds have been analyzed. The tests reveal that our treatment achieves the complete removal of crystal deposits and a total mean reduction of yeast presence. Moreover the wood composition of enological interest remains practically unaltered.

The use of the proposed treatment will reduce costs and the carbon footprint of the wine-making sector.
} 


\title{
Invited Technical Contribution
}

\section{Review on Monte Carlo Simulation Stopping Rules: How Many Samples Are Really Enough?}

\author{
Martin Bicher ${ }^{10000-0002-1362-6868](\square)}$, Matthias Wastian²[0000-0001-6291-2695], \\ Dominik Brunmeir 20000-0002-9005-4066], Matthias Rößler 20000-0002-4101-3129], and \\ Niki Popper ${ }^{321}$ \\ 1 Institute for Information Software Engineering, TU Wien, Favoritenstraße 9-11, 1040 \\ Vienna, Austria \\ martin.bicheretuwien.ac.at \\ 2 dwh GmbH, Neustiftgasse 57-59, 1070 Vienna, Austria \\ 3 DEXHELPP, Neustiftgasse 57-59, 1070 Vienna, Austria
}

\begin{abstract}
Due to extensive usage of stochastic simulation models correct execution of Monte Carlo simulation has become more and more important. Hereby the unknown real mean of the simulation result is estimated by the sample mean of a large number of simulation evaluations. Unfortunately, this procedure is often done carelessly. Modellers commonly use replication counts without scientific justification and sometimes underestimate the consequences of a bad or even wrong choice: if it is chosen too small, the sample mean is not a representative approximation for the regarded mean, and not only the simulation output, but also any kind of simulation analysis will not be representative at all. If the number is chosen too high, the Monte Carlo experiment will consume unnecessary computation time, which could, exemplarily, be invested into deeper model analysis instead. In this work, we present four methods that allow calculating an optimal replication number for Monte Carlo simulation and getting an image about the error between the estimated and the real mean value. The methods are furthermore evaluated on a simple case study, a stochastic cellular automaton model for simulation of an infectious disease.
\end{abstract}

Keywords: Monte Carlo Simulation, Stochastic Models, Stopping Rule, Cellular Automata 


\title{
Invited Technical Contribution
}

\section{Modelling landside logistic operations of a Megahub airport with discrete-event simulation}

\author{
Rodrigo Romero-Silva ${ }^{1[0000-0002-5912-1021](\boxminus)}$ Miguel Mujica Mota ${ }^{2[0000-0002-0160-6827]}$ \\ ${ }^{1}$ Supply Chain Analytics Department, Vrije Universiteit Amsterdam, De Boelelaan 1105, 1081 \\ HV, Amsterdam, The Netherlands \\ r.romerosilva@vu.nl \\ ${ }^{2}$ Aviation Academy, Amsterdam University of Applied Sciences, Weesperzijde 190, 1097 DZ \\ Amsterdam, The Netherlands \\ m.mujica.mota@hva.nl
}

\begin{abstract}
The need to better understand how to manage the real logistics operations in Schiphol Airport, a strategic hub for the economic development of the Netherlands, created the conditions to develop a project where academia and industry partnered to build a simulation model of the Schiphol Airport Landside operations. This paper presents such a model using discrete-event simulation. A realistic representation of the open road network of the airport as well as the (un)loading dock capacities and locations of the five ground handlers of Schiphol Airport was developed. Furthermore, to provide practitioners with applicable consolidation and truck-dispatching policies, some easy-to-implement rules are proposed and implemented in the model. Preliminary results from this model show that truck-dispatching policies have a higher impact than consolidation policies in terms of both distance travelled by cooperative logistic operators working within the airport and shipments' average flow time. Furthermore, the approach presented in this study can be used for studying similar megahubs.
\end{abstract}

Keywords: Consolidation, truck dispatching, airports, discrete-event simulation, logistics 


\title{
Invited Main Contribution
}

\section{Formal Methods and Simulation: Cooperation makes strength}

\author{
Manuel Silva \\ Instituto de Investigación en Ingeniería de Aragón (I3A), Universidad Zaragoza, Spain \\ silva@unizar.es
}

\begin{abstract}
A main part of my research activity concern formal methods in the field of concurrent discrete event [dynamic] systems (DES). This correspond to a "view" of dynamic systems where the state takes value in a discrete (possibly infinite) set and events play a fundamental role in its evolution (otherwise stated, DES are discrete-state and event-driven systems). Even if historically DES views start to develop dealing with artificial (i.e., human designed) systems, today they are also being applied to some natural ones (for a broad historical perspective on the DES field, with a certain bias towards system theory and control, [Silva (ed.), 2018]).

Petri Nets (PNs) - the modelling paradigm to which I devote most of my research attention concerning DESare transition systems that use a simple non-monotonous consumption-production logic. The interest on formal analysis and synthesis techniques in the PN framework is rooted on the many "surprising" behaviors (counter intuitive, "abnormal") that those classes of systems may exhibit. In order to prove correctness, the so called state explosion problem in their enumerative analysis (e. g., using model checking techniques) recommends the combination with transformation and structural techniques. However, when dealing with highly populated DES, the use of fluidization (a classical relaxation technique) may substantially reduce the computations, and provide "accurate enough" analysis of certain properties (the first book dealing with fluid approximations of Queuing Networks is [Newell, 1971], at that times introduced because the QN "literature [mainly] grew from solutions looking for a problem rather than from problems looking for a solution").

Fluid relaxations of PN models lead to particular classes of hybrid systems. When fluidization is total and the nets are considered under infinite server semantics, the relaxed models constitute a subclass of piecewise affine systems, more precisely with a polytopic partition in the state domain and continuity in their derivatives (the applicability of the fluidization of PN models depends on the particular properties under study and on the structure of the system under consideration [Silva, 2016]). Because I frequently hear about simulation with some reluctance, you can simply interpret this keynote as a praise for simulation, assuming it is made taking "enough care" (epistemological matters regarding computer-based simulations is a topic that deserve a number of works, from quite different perspectives; among other examples, [Tolk et al., 2013] and [Greca et al, 2014]). Moving first to "fully" continuous systems (even if limited to those modelled with ordinary differential equations, ODEs), we would like to remark that the probability of being able to integrate symbolically an ODE randomly generated is almost surely zero. Because many (most?) engineering problems are dynamically described with equations that have no primitive function, either linearization (an approximation at a certain point or along a certain trajectory) or numerical solution (another approximation) is a must. Paraphrasing [Cellier \& Kofman, 2006: vi], a terminological question is that "whereas applied mathematicians write about numerical ODEs", for analogous task "Engineers talk about simulation". The use in CSSL'67 of a command language to carry out experiments with ODEs is a first step towards the separation of the model and the experiment. However, in essence, as a language of sentences, it is more a language of simulation than of modeling.

Changing to the discrete-event systems modelling arena, it should be recognized that a pioneer use of the DES acronym came from discrete event simulation. In 1957, Keith D. Tocher appeared to be the first to conceive events as the required abstraction to characterize the kind of models we mention now (see, for example, [Hollocks, 2008]). Some two decades later, a "discrete-event model-driven" perspective was introduced in [Zeigler 1976], leading to a clear separation of the model construction from the proper simulation techniques (M\&S framework; PN-based simulation has always been essentially a model-driven approach). In the DES context, in spite of the numerous formal techniques for performance computation (exact, approximation or bounds), simulation remains a fundamental approach.

Nevertheless, problems like exploring the existence of an initial condition (initial marking in the PN terminology) making a DES deadlock-free (a non-monotonous property) is not reasonable to be addressed by simulation. Even more, the possible explanation for the absence of solution(s), if it is the case, needs some understanding from the structure of the PN model. Thus strong cooperation among formal techniques (that provide "understanding") and simulation (that in practice gives examples or counter examples of expected behaviors) is more than simply convenient.
\end{abstract}


As already pointed out, the continuous relaxation of DES formalized with PNs lead to some kind of technically hybrid models. Questions like, characterizing the continuity of the throughput in steady-state (if exist) of timed fluid PNs is also a question that requires the consideration of formal methods. Moreover, many conceptual explorations (like that of time-population duality) in order to gain understanding also requires formal analysis techniques. Nevertheless, the computation of the performance of most non-Markovian models necessitates some simulation.

In the previous statements, it is clear that we privilege Model-Based Design (i.e., building models instead of prototypes), not trial and error approaches. The rational in the use of knowledge-based models is to deal with safer and cheaper (also faster) to develop systems (including easier to repair and maintain). Simulating a model is "like" testing a prototype. Nevertheless, building models of (mainly of the environment of) certain systems may be a time consuming and inaccurate task. Moreover, transparency is a relevant concept on model management (see, for example, [Murray-Smith, 2016]). In model building, it is concerned with the "easiness" that someone not involved in its development can understand it. The goal is that their external users have a good understanding of how the model was built and organized, even what its limits ("entourage" of validity) are.

Looking more carefully to Data-Driven approaches, an emergent question is if such kind of representations can be more or less "automatically generated". The use of some Artificial Intelligence and model learning techniques applied to real data (somehow like "automatic identification") is a promising area. Even if in some cases provide good prediction accuracy ("usefulness"), they most usually suffer from insufficiency on model explainabilility (or explicability; "truthfulness" as a last goal); also scalability limitations should be taken into account. The lack of "explainability" of some Data- Driven approaches is currently a strong obstacle to their use, particularly in systems for which security is a must. Hybrid modelling solutions merging both approaches exist. For example, looking to enhance Model-Based designs with Data-Driven techniques [Tripakis, 2018].

Alfonso X el Sabio (the Wise) was a medieval king of Castile and Leon. He was very much interested on Astronomy. It is argued that, when the Ptolomy's geo-centric model of planetary motion (an "useful" model, as it have important predictive capabilities, but "not true") was explained to him, he react saying that (c. 1250):

If the Lord Almighty had consulted me before embarking upon his creation,

I should have recommended something simpler.

Probably that wise king will have a similar reaction looking to the complexity and size of many of the systems (e. g., cyber-physical, biological...) being considered as entities to analyze and control today. Even if the proof of correctness promise of formal methods is slowly becoming a reality in practice, simulations will most frequently remain an indispensable complementary tool.

\section{Some references}

[Cellier \& Kofman, 2006] François E. Cellier, and Ernesto Kofman: Continuous System Simulation, Springer Science+Business Media, Inc., NY, 2006.

[Greca et al, 2014] Ileana M. Greca, Eugenia Seoane, and Irene Arriassecq, "Epistemological Issues concerning Computer Simulations in Science and their implications for Science Education”, Science \& Education, vol. 23, 2014(4): 897-921.

[Hollocks, 2008] Brian W. Hollocks: "Intelligence, innovation and integrity. KD Tocher and the dawn of simulation", Journal of Simulation, vol. 23, 2008(3): 128-137.

[Murray-Smith, 2016] David J. Murray-Smith: "Issues of Transparency, Testing and Validation in the Development and Application of Simulation Models", Simulation Notes Europe, SNE, vol. 26, 2016(2): 57-65.

[Newel, 1971] Gordon F. Newell, Applications of Queuing Theory (Monographs on Applied Probability and Statistics), London Chapman and Hall, 1971.

[Silva, 2016] Manuel Silva: "Individuals, populations and fluid approximations: A Petri net based perspective", Nonlinear Analysis: Hybrid Systems, vol. 22, 2016: 72-97.

[Silva (ed.), 2018] Manuel Silva (ed): "Special section on the history of Discrete Event Systems", Annual Reviews in Control: vol. 45, Spring 2018: 211-280.

[Tolk et al., 2013] A. Tolk, B. Heath, M. Ihrig, J. Padilla, E. Page, E. Suárez, C. Szabo, P. Weirich, and L. Yilmaz, "Epistemology of Modeling and Simulation", Proceedings of the Winter Simulation Conference (Piscataway, New Jersey: IEEE), 2013: 1152- 1166.

[Tripakis, 2018] Stavros Tripakis: "Data-Driven and Model-Based Design”, 1st IEEE International Conference on Industrial Cyber-Physical Systems (ICPS 2018), 2018: 103-108.

[Ziegler, 1976] Bernard P. Zeigler, Theory of modeling and simulation, John Wiley, 1976. 


\title{
Invited Main Contribution
}

\section{Renewable sources-based smart micro grids with hydrogen as backup: modeling, control, implementation and management. A real case}

\author{
José Manuel Andújar Universidad de Huelva, Spain \\ andujar@uhu.es
}

\begin{abstract}
This conference deals with the complex problem of designing and putting into work an electrical grid where the primary sources (principally sun and wind) are intermittent and sometimes difficult to predict but, however, whereas mandatory, the users must have the guaranteed supply. As sources and backup systems grow, especially if they are of different types, the grid freedom degrees also grow, and consequently its capacity to guarantee the supply, but, the complexity of the modelling, control, implementation and management as well. Thus, introducing intelligence to the network in order to make it operational seems unavoidable, but..., what is the meaning of smart grid?

Well, let's start from the beginning; the concept of distributed generation, very close to consumption points, usually produced by small power plants, has led to what is known as micro grids. When a micro grid includes control and management smart technology becomes a smart micro grid. The term smart means that the micro grid has a control system with its own energy management strategy that is able to match demand, increases the lifetime of the elements, reduces operating costs and maximizes the microgrid performance. The concepts of micro grid and smart micro grid seem to be a perfect match for renewable energies.

Firstly, because renewable energy is essentially distributed and different depending on the place; and secondly, because renewable energy is intermittent. Therefore, in order to assure a continuous supply with quality, hybridizing different renewable sources and equipping the whole system with intelligent technologies for getting the proper performance.

In this conference, we are going to present a methodological foundation for modelling and designing a model predictive control (MPC) applied to renewable sources-based micro grids with hydrogen as backup. The goal of the MPC is to guarantee the best energy distribution and, in order to optimize the micro grid operation, technical and economic parameters have been included in the modelling process. Then, putting together the developed model and thedesigned MPC, a regulated operation of the micro grid is guaranteed during all its operating scope at the time that it meets with the energy demand saving the useful lifetime of its elements, while the most economical benefit as possible is obtained. Thisis, as the result of the modelling methodology and the designed MPC, it is conceivable to optimize the micro grid operation both in the short- and in the longterm basis. The micro grid model and the designed MPC controller have been validated in an actual smart micro grid, specifically in the University of Huelva's smart micro grid. In fact this is its current controller.
\end{abstract}




\title{
Invited Main Contribution
}

\section{Nature, Features and Properties of Developments in Modelling and Simulation - from $A$-Alternative to $Z$ - Zippy}

\author{
Felix Breitenecker, Technical University Vienna, Mathematical Modelling and Simulation \\ Group, Vienna, Austria \\ felix.breitenecker@tuwien.ac.at
}

\begin{abstract}
The development of modelling and simulation has gone various ways. Shannon's definition for simulation as

the process of designing a model of a real system and conducting experiments with

this model for the purpose either of understanding the behaviour of the system

or of evaluating various strategies for the operation of the system

allows developments of different nature and invites for application in any area.

Furthermore, computer advance and software improvement have stimulated the development of system simulation essentially. Consequently, the development of modelling and simulation shows different nature, various features, and characteristic properties.

Nature, features and properties of modelling and simulation development may range from A to Z, the following incomplete list includes also controversial features and properties:

- adjustable, alternative, behavioural, classical, conservative, controversial,

- delayed, direct, dogmatic, early, expected, exiting, exotic, fascinating,

- generic, helpful, improper, joyous, keen, late, limited, meaningful,

- necessary, needless, novel, obsolete, pragmatic, puzzling,

- reasonable, recycled, reused, special, standard, straightforward,

- strange, surprising, tricky, typical, untimely, unusual, various, wanted,

- willing, $\mathrm{x}$-fold, yielding, zany, zippy, etc.
\end{abstract}

This contribution picks out features and properties with unusual and conflictive character as

- straightforward vs surprising,

- expected vs coincidental,

- novel vs recycled,

- classic vs exotic,

- boon and bane,

- dogmatic vs adjustable,

- necessary vs needless,

- early vs late, etc

and discusses and documents them by new and elder publications, and by case studies. Interestingly, this approach allows different views and alternative insights into topics as nonlinearity, model analysis, algorithms, simulation software, numerics, causality, etc.

An oral presentation of this contribution may last from ten minutes to three hours. For a proper and timecontrolled presentation course the audience is invited to select the features and properties to be presented and to be discussed discuss - by use of a stochastic process. 


\section{SNE - Simulation Notes Europe}

EUROSIM, the Federation of European Simulation Societies provides a European forum for regional and national simulation societies to promote the advancement of modelling and simulation in industry, research and development.

Under the EUROSIM umbrella, EUROSIM Member Societies and co-operating societies and groups organise conferences, produce publications on modelling and simulation, work in standardising or technical committees, etc. Main event of EUROSIM it the EUROSIM CONGRESS, which is arranged every three years by a member society of EUROSIM.

The scientific Journal SNE - Simulation Notes Europe is the official scientific membership journal of EUROSIM. SNE provides an international, high-quality forum for presentation of new ideas and approaches in simulation - from modelling to experiment analysis, from implementation to verification, from validation to identification, from numerics to visualisation - in context of the simulation process. SNE puts special emphasis on the overall view in simulation, and on comparative investigations. Furthermore, SNE welcomes contributions on education in/for/with simulation.

SNE is also the forum for the ARGESIM Benchmarks on Modelling Approaches and Simulation Implementations publishing benchmarks definitions, solutions, reports and studies - including model sources via web.

SNE, primarily an electronic journal, follows an open access strategy, with free download in basic layout. SNE is the official membership journal of EUROSIM, the Federation of European Simulation Societies.

Members of EUROSIM Societies are entitled to download SNE in high-quality, and to access additional sources of benchmark publications, model sources, etc.

On the other hand, SNE offers EUROSIM Societies a publication forum for postconference publication of the society's international conferences, and the possibility to compile thematic or event-based SNE Special Issues.

Simulationists are invited to submit contributions of any type - Technical Note, Short Note, Project Note, Educational Note, Benchmark Note, etc. via SNE's website:

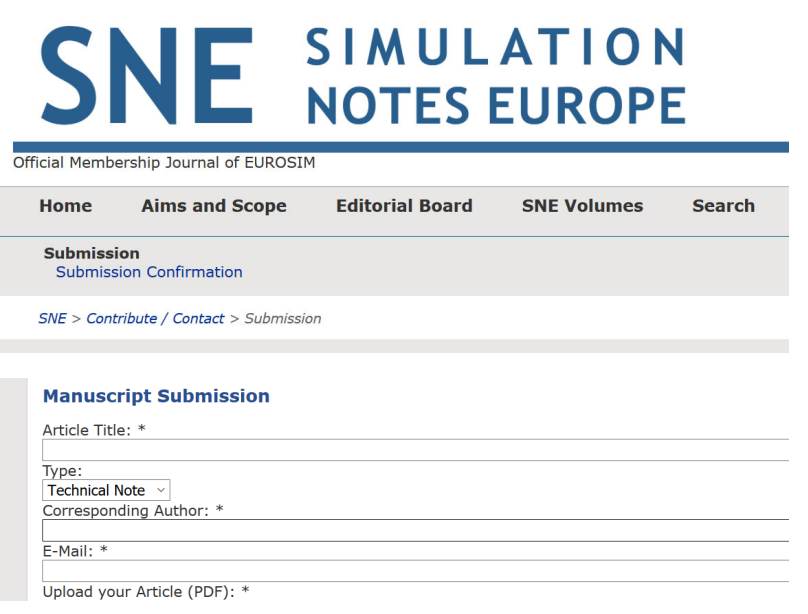

$\rightarrow$ www.sne-journal.org,

童” $\rightarrow$ office@sne-journal.org, eic@sne-journal.org

$\varangle \rightarrow$ SNE Editorial Office, ARGESIM/Math. Modelling \& Simulation Group, Inst. of Analysis and Scientific Computing TU Wien, Wiedner Hauptstrasse 8-10 1040 Vienna, Austria

EiC Prof. Dr. Felix Breitenecker 


\section{**** EUROSIM 2019 $10^{\text {th }}$ EUROSIM Congress on Modelling and Simulation La Rioja, Logroño, Spain, July 1 - 5, 2019}
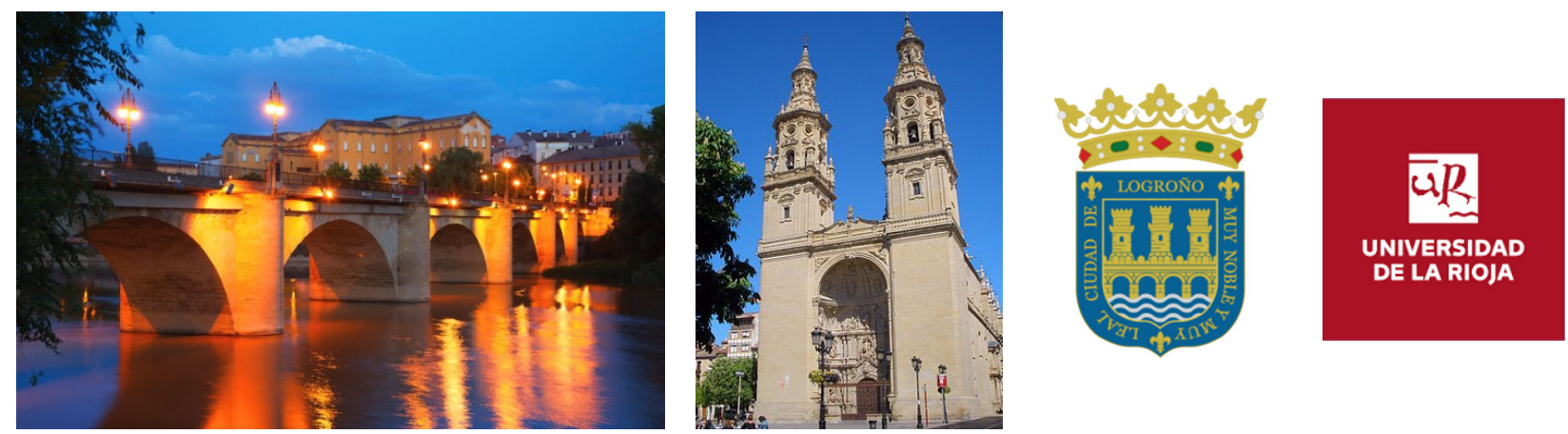

EUROSIM Congresses are the most important modelling and simulation events in Europe. For EUROSIM 2019, we are soliciting original submissions describing novel research and developments in the following (and related) areas of interest: Continuous, discrete (event) and hybrid modelling, simulation, identification and optimization approaches. Two basic contribution motivations are expected: M\&S Methods and Technologies and M\&S Applications.

Contributions from both technical and non-technical areas are welcome.

Congress Topics The EUROSIM 2019 Congress will include invited talks, parallel, special and poster sessions, exhibition and versatile technical and social tours. The Congress topics of interest include, but are not limited to:

\author{
Intelligent Systems and Applications \\ Hybrid and Soft Computing \\ Data \& Semantic Mining \\ Neural Networks, Fuzzy Systems \& \\ Evolutionary Computation \\ Image, Speech \& Signal Processing \\ Systems Intelligence and \\ Intelligence Systems \\ Autonomous Systems \\ Energy and Power Systems \\ Mining and Metal Industry \\ Forest Industry \\ Buildings and Construction \\ Communication Systems \\ Circuits, Sensors and Devices \\ Security Modelling and Simulation
}

Bioinformatics, Medicine, Pharmacy and Bioengineering

Water and Wastewater Treatment Sludge Management and Biogas Production

Condition monitoring, Mechatronics and maintenance

Automotive applications

e-Science and e-Systems

Industry, Business, Management, Human Factors and Social Issues

Virtual Reality, Visualization, Computer Art and Games

Internet Modelling, Semantic Web and Ontologies

Computational Finance \& Economics
Simulation Methodologies and Tools

Parallel and Distributed

Architectures and Systems

Operations Research

Discrete Event Systems

Manufacturing and Workflows

Adaptive Dynamic Programming

and Reinforcement Learning

Mobile/Ad hoc wireless

networks, mobicast, sensor

placement, target tracking

Control of Intelligent Systems

Robotics, Cybernetics, Control

Engineering, \& Manufacturing

Transport, Logistics, Harbour, Shipping and Marine Simulation

Congress Venue / Social Events The Congress will be held in the City of Logroño, Capital of La Rioja, Northern Spain. The main venue and the exhibition site is the University of La Rioja (UR), located on a modern campus in Logroño, capital of La Rioja, where 7500 students are registered. The UR is the only University in this small, quiet region in Northern Spain. La Rioja is where the Monasteries of San Millán de la Cogolla, cradle of the first words written in the Spanish language, are situated, sites included in UNESCO's World Heritage List in 1996. Of course, social events will reflect this heritage - and the famous wines in la Rioja.

Congress Team: The Congress is organised by CAE CAE-SMSG, the Spanish simulation society, and Universidad de la Rioja.

Info: Emilio Jiménez, EUROSIM President, emilio.jimenez@unirioja.es Juan Ignacio Latorre, juanignacio.latorre@unavarra.es 